\title{
Enabling Technology for Monitoring \& Predicting Gas Turbine Health $\&$ Performance in COAL IGCC Powerplants
}

\section{Technical Progress Report}

For Semi-Annual Period

Beginning April 1, 2004

Ending August 31, 2004

Submitted To: US Department of Energy

National Energy Technology Laboratory

Morgantown, WV 26507-0880

Submitted By: GE Energy

Schenectady, NY. 12345

September 30, 2004

DOE Cooperative Agreement No. DE-FC26-03NT41448 


\section{DISCLAIMER}

This report was prepared as an account of work sponsored by an agency of the United States Government. Neither the United States Government nor any agency thereof, nor any of their employees, makes any warranty, express or implied, or assumes any legal liability or responsibility for the accuracy, completeness, or usefulness of any information, apparatus, product, or process disclosed, or represents that its use would not infringe privately owned rights. Reference herein to any specific commercial product, process, or service by trade name, trademark, manufacturer, or otherwise does not necessarily constitute or imply its endorsement, recommendation, or favoring by the United States Government or any agency thereof. The views and opinions of authors expressed herein do not necessarily state or reflect those of the United States Government or any agency thereof. 


\begin{abstract}
The "Enabling \& Information Technology To Increase RAM for Advanced Powerplants" program, by DOE request, has been re-directed, de-scoped to two tasks, shortened to a 2-year period of performance, and refocused to develop, validate and accelerate the commercial use of enabling materials technologies and sensors for Coal IGCC powerplants. The new program has been re-titled as "Enabling Technology for Monitoring \& Predicting Gas Turbine Health \& Performance in IGCC Powerplants" to better match the new scope. This technical progress report summarizes the work accomplished in the reporting period April 1, 2004 to August 31, 2004 on the revised Re-Directed and De-Scoped program activity. The program Tasks are summarized below:

Task 1- IGCC Environmental Impact on high Temperature Materials:

This first materials task has been refocused to address Coal IGCC environmental impacts on high temperature materials use in gas turbines and remains in the program. This task will screen material performance and quantify the effects of high temperature erosion and corrosion of hot gas path materials in Coal IGCC applications. The materials of interest will include those in current service as well as advanced, high-performance alloys and coatings.

\section{Task 2 - Material In-Service Health Monitoring}

This second task develops and demonstrates new sensor technologies to determine the in-service health of advanced technology Coal IGCC powerplants, and remains in the program with a reduced scope. Its focus is now on only two critical sensor need areas for advanced Coal IGCC gas turbines: 1) Fuel Quality Sensor for detection of fuel impurities that could lead to rapid component degradation, and a Fuel Heating Value Sensor to rapidly determine the fuel heating value for more precise control of the gas turbine, and 2) Infra-Red Pyrometer to continuously measure the temperature of gas turbine buckets, nozzles, and combustor hardware.
\end{abstract}




\section{TABLE OF CONTENTS}

Disclaimer $\quad$ i

$\begin{array}{ll}\text { Abstract } & \text { ii }\end{array}$

Table of Contents

$\begin{array}{ll}\text { Figures and Tables } & \text { iv, v }\end{array}$

$\begin{array}{lll}1.0 & \text { Introduction } & 1\end{array}$

$\begin{array}{lll}2.0 & \text { Executive Summary } & 2\end{array}$

3.0 Experimental 3

Task $1+3$

$\begin{array}{lr}\text { Task } 2 & 10\end{array}$

\begin{tabular}{ll} 
4.0 & Results and Discussion \\
\hline
\end{tabular}

$\begin{array}{ll}\text { Task } 1 & 17\end{array}$

$\begin{array}{ll}\text { Task } 2 & 30\end{array}$

$\begin{array}{lll}5.0 & \text { Conclusion } & 38\end{array}$

$\begin{array}{ll}\text { Task } 1 & 38\end{array}$

$\begin{array}{ll}\text { Task } 2 & 38\end{array}$

$\begin{array}{lll}\text { 6.0 } & \text { References } & 39\end{array}$

$\begin{array}{lll}\text { 7.0 } & \text { List of Acronyms and Abbreviations } & 40\end{array}$ 


\section{Figures and Tables}

\section{Figures:}

Figure 3.1.1: $\quad$ Lexan ${ }^{\circledR}$ chamber to be fabricated for use with inert gas experiments 9

Figure 3.2.1: Laboratory based testing station showing four mass flow controllers 12 (MFCs) at the top and piping leading to the LHV sensor

Figure 3.2.2: $\quad$ Five pyrometers on the PSI-Cinergy Wabash River 7FA gas turbine 13

\begin{tabular}{ll} 
Figure 3.2.3: & UG utility flow chart \\
\hline
\end{tabular}

$\begin{array}{lll}\text { Figure 3.2.4: } & \text { Sensor fixture with orifices and related plumbing } & 16\end{array}$

Figure 4.1.1: Cross section of Stage 1 bucket leading edge showing typical high 22 temperature oxidizing surface reactions

Figure 4.1.2: Cross section of Stage 1 bucket leading edge showing atypical surface 22 reactions

Figure 4.1.3: Higher magnification of the same area depicted in figure 4.1.2. 23

Figure 4.1.4: Surface oxidation observed in an unstressed DS GTD-111 23

Figure 4.1.5: Predictions for (a) isothermal LCF and (b) TMF of L DS GTD-111 27

Figure 4.1.6: (a) A debonded carbide on the fracture surface (longitudinal specimen, 29 $1600{ }^{\circ} \mathrm{F}$, continuous cycling) and (b) Inclusion on the fracture surface acting as a crack initiation site

Figure 4.1.7: Chemical composition of a carbide inclusion on the fracture surface 29

Figure 4.2.1: Sensor requirements for Coal IGCC gas turbines 31

Figure 4.2.2: $\quad$ Combustion effects on ethane and $\mathrm{CO}_{2}$

Figure 4.2.3: LHV sensor signal responding to varying concentrations of ethane 32

Figure 4.2.4: Combustion affects on $\mathrm{CO} 33$

Figure 4.2.5: Percent change of natural gas constituents by concentration 34

Figure 4.2.6: Sensor output versus time 34

$\begin{array}{lll}\text { Figure 4.2.7: } & \text { LHV sensor output versus time } & 37\end{array}$ 


\section{Tables:}

Table 3.1.1: $\quad$ Pre-Exposure Fatigue Tests $\quad 7$

Table 3.1.2: $\quad$ Fatigue Damage Tests $\quad 7$

Table 3.1.3: $\quad$ Oxidation-Fatigue Damage Tests 8

Table 3.1.4: $\quad$ TGA Tests 9

Table 4.1.1: $\quad$ Summary of Results at Syngas Location 1 (Pre-filter) 19

Table 4.1.2: $\quad$ Summary of Results at Syngas Location 2 (Post-filter) 20

Table 4.1.3: $\quad$ Summary of Results for Strainer Rinse 21

Table 4.1.4: Service conditions for the Stage 1 and two Stage 2 buckets provided by 21 TECo

Table 4.1.5: Constants for the Crack Initiation Model 27

Table 4.2.1: $\quad$ PSI-Cinergy IGCC gas turbine pyrometer calibration details 35 


\subsection{Introduction}

\section{Enabling Technology for Monitoring and Predicting Gas Turbine Health and Performance in IGCC Powerplants}

\section{Objective:}

Materials and sensors for advanced technology Coal IGCC (Integrated Gasification Combined Cycle) powerplants will be evaluated and demonstrated at a U.S powerplant. These technologies are critical for meeting the DOE targets for Coal IGCC powerplant performance, emissions, reliability, and cost. The project will also benefit advanced technology gas-fired and dual fuel powerplants via spin-off of new technologies.

\section{Background:}

The project will develop, validate and accelerate the commercial use of enabling technologies for advanced technology Coal IGCC powerplant condition assessment and condition based maintenance. The purpose of condition assessment is the real-time, automatic extraction of useful information from operating data to guide decisions, which differentiates it from traditional powerplant monitoring. By contrast, condition based maintenance relies upon the use of this derived information, along with analytical models of part degradation, to accurately predict capital parts consumption and plan maintenance outage schedules

\section{Relevancy:}

Significant benefits to the U.S. public will be additional electricity delivered to the power grid, with fewer interruptions, particularly during periods of peak demand; and reduced generation cost resulting from lower equipment maintenance costs, lower insurance premiums, more stable and reliable power transmission and distribution, and shorter learning curves when new power generation technologies are introduced to the market. Additional benefits include significant reduction in pollutants and improved capability for burning a wide variety of gaseous and liquid fuels in advanced power plants. These advances will benefit future Coal IGCC powerplants and existing natural gas powerplants.

Period of Performance: March 01, 2003 to February 28, 2005 


\subsection{Executive Summary}

The newly Re-directed and De-scoped "Enabling Technology for Monitoring \& Predicting Gas Turbine Health \& Performance in IGCC Powerplants" program will develop, validate and accelerate the commercial use of enabling materials technologies and sensors for Coal IGCC powerplants. This is being accomplished in two basic tasks. The initial materials task will screen material performance and quantify the effects of high temperature erosion and corrosion of hot gas path materials in Coal IGCC applications. The materials of interest will include those in current service as well as advanced, high-performance alloys and coatings. The second sensors task will focus on two critical needs for advanced Coal IGCC gas turbines: 1) Fuel Quality Sensor to rapidly determine the fuel heating value for more precise control of the gas turbine, and detection of fuel impurities that could lead to rapid component degradation. 2) Infra-Red Pyrometer to continuously measure the temperature of gas turbine buckets, nozzles, and combustor hardware. This revised program consists of the following two tasks:

\section{Task 1- IGCC Environmental Impact on High Temperature Materials:}

The first materials task has been refocused to address Coal IGCC environmental impacts on high temperature materials used in gas turbines and remains in the program. This task will screen material performance and quantify the effects of high temperature erosion and corrosion of hot gas path materials in Coal IGCC applications. The materials of interest will include those in current service as well as advanced, high-performance alloys and coatings.

\section{Task 2 - Material In-Service Health Monitoring}

This second task develops and demonstrates new sensor technologies to determine the in-service health of advanced technology Coal IGCC powerplants, and remains in the program with a reduced scope. Its focus is now on only two critical sensor need areas for advanced Coal IGCC gas turbines: 1) Fuel Quality Sensor for detection of fuel impurities that could lead to rapid component degradation, and a Fuel Heating Value Sensor to rapidly determine the fuel heating value for more precise control of the gas turbine, and 2) Infra-Red Pyrometer to continuously measure the temperature of gas turbine buckets, nozzles, and combustor hardware.

This report summarizes the work accomplished in the April 1, 2004 to August 31, 2004 and includes progress details from each of the Tasks. 


\subsection{Experimental}

This section presents a descriptive summary of the experimental methods in use for the conduct of this project. Described below are the experimental methods by Task, and where appropriate, by Sub-task, that were used for the research efforts during this reporting period. Not all subtasks may have been initiated during this reporting period of the program, and are so noted.

\section{Task 1: IGCC Environmental Impact on High Temperature Materials:}

Material selection, test planning, purchase of raw material, specimen machining and preliminary specimen analyses are in progress. 80 slabs of directionally solidified GTD111 were purchased and 20 of these slabs have thus far received the proper heat treatment. The planned experiments will include oxidation, hot corrosion, sulfidation, erosion, low cycle fatigue, fracture toughness, thermo-mechanical fatigue, fatigue crack growth and the interactions between the environmental and mechanical properties. Additionally, coating effects will be evaluated along with microstructural evaluation of specimens and field hardware. The testing is to be accomplished at accredited test laboratories, including Georgia Tech and GE Global Research, in accordance with published ASTM standards for mechanical testing. In addition, Stage 1 buckets and Stage 2 buckets were received from TECo for evaluation, all with one service cycle ( 24000 hours) of operation.

\section{Service Exposed Material}

The ability to correlate laboratory data to gas turbine parts in service is of paramount importance in this investigation. To understand the environmental effects on high temperature materials in a Coal IGCC power plant, two sets of data must be analyzed. The first is to determine the corrosion products present on the surface of the gas turbine parts after a known service exposure time. Tampa Electric Company (TECo) has provided two Stage 1 buckets and two Stage 2 buckets from their 7FA Coal IGCC gas turbine for destructive analysis. This analysis will consist of micro-structural observation of the surface and cross-section of the part and spectroscopy to determine the composition of the surface and near surface layers. The second data set needed is the environmental conditions responsible for producing the surface reactions observed on the service parts. Both of these sets of data will be collected and analyzed in this study to facilitate the correlation of service data to laboratory data.

\section{Burner Rig Experiments}

Burner rigs are used to simulate the environment in a gas turbine. Rather than simply exposing a specimen to high temperature in air, a burner rig also introduces combustion products to the specimen. The inclusion of combustion products is to more closely simulate the actual environment encountered by the alloy in a gas turbine. The alloys and alloy/coating systems that will be tested by GE Energy in Schenectady, NY are:

- Rene N5

- Rene N5 + NiCrAlY coating

- GTD111

- GTD111 + CoNiCrAlY coating

- GTD222

- FSX414 
- Nimonic 263

- Nimonic $263+$ CoNiCrAlY coating

- Hastelloy X

\section{Controlled Environment Experiments}

$\mathrm{CC}$ Technologies of Dublin, $\mathrm{OH}$ will be performing controlled environment experiments on the nine candidate alloys/coatings (listed above). The tests will be conducted in three gaseous environments at a temperature of approximately 1800 to $2000^{\circ} \mathrm{F}$. The gaseous environments to be utilized in this project are as follows:

1. Oxidation investigation: dry air

2. Sulfidation investigation/1: $\mathrm{N}_{2}$ with $100 \mathrm{ppm} \mathrm{H}_{2} \mathrm{~S}$

3. Sulfidation investigation/2: $\mathrm{N}_{2}$ with 100ppm $\mathrm{H}_{2} \mathrm{~S}$ and $\mathrm{H}_{2} \mathrm{O}$ vapor

In order to determine the growth kinetics of the oxide and/or sulfide films on the alloy, four exposure periods are required for each test environment: $10 \mathrm{hr}, 30 \mathrm{hr}, 100 \mathrm{hr}$ and $300 \mathrm{hr}$. The film growth will be followed by gravimetric measurements.

CC Technologies will setup two flow-through tubular reactors, or systems, for the high temperature gas testing of the candidate alloys. Each system will consist of a horizontal 2-inch diameter alumina reactor housed in a tubular furnace, which will have three independently controlled heating zones equipped with appropriate temperature controllers and a high temperature alarm. The maximum operating temperature of the reactor will be $2000^{\circ} \mathrm{F}$.

The tubular reactor will operate in a once-through flow mode with the appropriate gas mixture. Both of the gas mixtures will be procured commercially. The flow rate of a gas mixture through the reactor is expected to be in the range of $1-10 \mathrm{cc} / \mathrm{min}$ at room temperature, but the exact flow rate will be decided later. In the case of the wet gas mixture (environment \#3), the dry gas mixture will be first bubbled through a de-ionized (DI) water bath that will be maintained at room temperature. This will saturate the gas mixture with water vapor prior to entry into the test reactor. The working zone in the tubular reactor will be approximately 12 inches long. Special trays of alumina will be used to hold the test coupons in the working zone and keep them isolated from each other. The holder will be designed such that at least 15 coupons can be accommodated at one time in the working zone of the reactor. Thus, the tray capacity will dictate the coupon loading schedule.

Prior to loading, the coupons will be photographed in the as-received condition. The various sets of coupons will be re-photographed after removal from the reactor. Weight change of the coupon will be determined using an analytical balance. A set of three readings will be taken for each coupon. A kinetic rate model for the film growth will be developed for each alloy based on its weight change data. Following the tests and measurements, the coupons will be returned by CC Technologies along with a test report. The report will contain the test results and photographs, and oxide growth rate for each of the test alloys. Upon return, subsequent microscopy and spectroscopy will be performed to fully characterize the results. 


\section{Erosion Experiments}

GE Aircraft Engines in Evendale, $\mathrm{OH}$ will conduct high temperature erosion experiments on the following material/coating systems:

- Rene N5 + NiCrAlY bondcoat + air plasma sprayed TBC

- GTD111 + CoNiCrAlY bondcoat + air plasma sprayed TBC

- Nimonic-263 + CoNiCrAlY bondcoat + air plasma sprayed TBC

The tests will determine the amount of erosion resistance the above coatings systems possess, under conditions that simulate the gas turbine.

\section{Syngas Sampling}

Syngas fuel sampling tests were performed on June 5-7, 2004 at the Tampa Electric Company (TECo) Polk 1 powerplant, located near Mulberry, FL. The purpose of the fuel sampling was to evaluate the effect of Syngas fuel constituents and contaminants on the service lives of gas turbine combustion and downstream turbine components during actual operating conditions. Typical Coal IGCC Syngas contains a gaseous mixture of mostly combustible constituents such as $\mathrm{CO}, \mathrm{H}_{2}$, and $\mathrm{CH}_{4}$, plus non-combustible gases such as $\mathrm{CO}_{2}, \mathrm{~N}_{2}, \mathrm{Ar}$ and $\mathrm{H}_{2} \mathrm{O}$, and small quantities of compounds of sulfur (20 to $200 \mathrm{ppm})$. During gasification plant start up and operational transients, the Syngas may contain additional contaminants, such as compounds of iron, nickel, calcium, sodium and potassium, ammonia, volatile compounds of mercury, $\mathrm{HCl}$, arsenic, etc. The gas turbine fuel and exhaust gas streams will be sampled at regular intervals. Results from this task will allow the formulation of predictive models to correlate the observed fuel variation with the observed part condition.

Cubix Corporation sampled for combustible gases, particulate matter (PM), metals, HCl, Ammonia $\left(\mathrm{NH}_{3}\right)$, and sulfur species at two locations on the Syngas fuel line to the GE MS$7001 \mathrm{~F}$ gas turbine. Three test runs were performed simultaneously at each location: pre-filter and post-filter. The first two runs were performed during startup of the gas turbine. The third run was performed when the turbine was at full load. A total of six Syngas samples were taken.

Syngas fuel residue samples were taken from the Syngas fuel filter and gas turbine fuel strainer during gasifier/gas turbine shutdown. The strainer was removed and rinsed with deionized (DI) water and $0.1 \mathrm{~N}$ Nitric acid. Each sample was collected in stainless steel sample cylinders. The DI water was analyzed for $\mathrm{Cl}, \mathrm{NO}_{3}$ and $\mathrm{SO}_{4}$. The DI waste and the nitric acid were mixed, and this mixture was analyzed for metals by Chester LabNet. The list of metals included As, Ca, Fe, $\mathrm{Hg}, \mathrm{Ni}, \mathrm{K}$ and $\mathrm{Na}$. These samples were analyzed for sulfur species (ASTM D-5504) and fuel composition (UOP-539) by Core Laboratories of Houston, TX.

Particulate matter was collected over two sampling periods. The first sampling period included runs 1 and 2. The second sampling period included run 3. The particulate matter samples were analyzed for gravimetric weight gain and PM metals (As, $\mathrm{Ca}, \mathrm{Fe}, \mathrm{Hg}, \mathrm{Ni}, \mathrm{K}$ and $\mathrm{Na}$ ). Particulate matter testing followed EPA isokinetic techniques. However, due to the unusual source and sampling conditions, a custom sampling apparatus was used to accommodate the high flow necessary to sample isokinetically. The sample was extracted from the Syngas fuel line through a $1 / 4$ " ID sampling nozzle installed in the pipe. The sample flowed from the nozzle through stainless steel tubing and several shut off valves to the PM sampling apparatus. PM was 
collected on a $47 \mathrm{~mm}, 0.2 \mu \mathrm{m}$ porosity, quartz fiber filter contained in a heated enclosure. Sample flow was measured with a $3 / 8$ " orifice plate. The flow was controlled using stainless steel needle valves. Isokinetic sample rates were determined from the sample flow and the Syngas fuel flow in the fuel line. The particulate matter filters were analyzed by Chester LabNet of Tigard, OR for gravimetric weight gain and metals.

Ammonia $\left(\mathrm{NH}_{3}\right)$ and $\mathrm{HCl}$ was collected from the Syngas into an impinger train containing $0.1 \mathrm{~N}$ sulfuric acid. Impinger samples were analyzed for $\mathrm{NH}_{3}$ analysis was performed at Cubix's Austin Laboratory. An aliquot of the impinger solution was sent to Chester LabNet for $\mathrm{HCl}$ analysis. The $\mathrm{HCl}$ analysis was performed using Ion Chromatography (IC) following the procedures in EPA Method 26A.

The analysis for gaseous metals followed the procedures of EPA Method 29. As, Ca, Fe, $\mathrm{Hg}, \mathrm{Ni}$, $\mathrm{K}$ and $\mathrm{Na}$ were collected from the Syngas into an impinger train. The impinger samples were sent to Chester LabNet for analysis. Hg was analyzed using cold vapor atomic absorption. The other metals were analyzed by a Inductively-Coupled Plasmaspectrometer (ICP).

Deliverables: Actual and corrected experimental results of test data (flow, pressure, temperature and composition) will be reported for the following streams:

1. Fuel Gas stream immediately upstream of Syngas Fuel Filter

2. Fuel Gas stream immediately upstream of Syngas Fuel Skid

3. Gas stream immediately downstream of Gas Turbine Exhaust Duct

4. Residue composition and constituents of Syngas Fuel Filter

5. Residue composition and constituents of Gas Turbine Fuel Gas Strainer

\section{Georgia Institute of Technology}

Characterization of unstressed microstructure with environmental exposure

Isothermal exposures of stress-free coupon sample discs were conducted in a 3-zone tubular electric resistance furnace. A total of 27 directionally solidified (DS) GTD-111 discs were exposed to $871^{\circ} \mathrm{C}\left(1600^{\circ} \mathrm{F}\right), 982^{\circ} \mathrm{C}\left(1800^{\circ} \mathrm{F}\right)$, and $1038^{\circ} \mathrm{C}\left(1900^{\circ} \mathrm{F}\right)$ in static air. The exposure time ranged from 1 to 1000 hours.

\section{Effect of pre-exposure on residual low cycle fatigue strength}

The influence of thermal/mechanical pre-exposure on deformation, life, and crack initiation has not been considered in the development of existing fatigue crack initiation models; however, the effects of pre-rafting and pre-exposure prior to fatigue testing are quite significant, since up to $50 \%$ of life can be lost or gained via pre-exposure to a creep strain of at most $0.4 \%$ in tension or compression, respectively. To attain the desired rafted microstructure and/or surface condition, a comparable level of inelastic deformation under uniaxial tensile loading lasting $100 \mathrm{hr}$. is needed for DS GTD-111.

The details of planned testing are given in Tables 3.1.1 and 3.1.2. Several tests are suggested for each orientation. Configurations of these experiments will include pre-exposure to two high temperatures in either static air or a sulfidizing environment that is representative of a Coal IGCC combustion products. This environment contains particulates and contaminates (e.g. $\mathrm{H}_{2} \mathrm{~S}$ and COS) as well as high levels of moisture in the combustion gas. The mechanical strain range will vary from $0.5 \%$ to $1.0 \%$. To isolate the role of the microstructure on crack initiation life, 
some samples will be polished after pre-exposure and subsequently fatigue-tested in an inert gas environment. This procedure eliminates the effects of surface cracking. Lives and deformation data from tests in Tables 3.1.1 and 3.1.2 will be compared.

Table 3.1.1 Pre-Exposure Fatigue Tests

\begin{tabular}{|c|c|c|c|c|c|}
\hline \multicolumn{2}{|c|}{ Pre-Exposure } & \multicolumn{4}{|c|}{ Fatigue Test } \\
\hline $\begin{array}{l}\text { Temperature } \\
\left({ }^{\circ} \mathrm{C}\right) \text { and } \\
\text { Environment }\end{array}$ & $\begin{array}{c}\text { Mechanical } \\
\text { Pre-Load } \\
(\mathrm{MPa})\end{array}$ & $\begin{array}{c}\text { Temperature } \\
\left({ }^{\circ} \mathrm{C}\right)\end{array}$ & $\begin{array}{c}\text { Mechanical } \\
\text { Strain Range } \\
\Delta \varepsilon_{m}(\%)\end{array}$ & Environment & Hold Type \\
\hline \multirow[t]{2}{*}{$982 \mathrm{Ar}+2.9 \% \mathrm{H}_{2}$} & -100 & \multirow[t]{2}{*}{871} & \multirow[t]{2}{*}{0.8} & $\mathrm{Ar}+2.9 \% \mathrm{H} 2$ & \multirow[t]{2}{*}{ None } \\
\hline & $\begin{array}{c}100 \\
-100\end{array}$ & & & & \\
\hline & & & & & \\
\hline $1093 \mathrm{Ar}+2.9 \% \mathrm{H} 2$ & $\frac{-100}{100}$ & 871 & & $\mathrm{Ar}+2.9 \% \mathrm{H} 2$ & \\
\hline 982 IGCC & $\overline{0}$ & \multirow[t]{5}{*}{871} & \multirow[t]{5}{*}{0.8} & Air & \multirow[t]{5}{*}{ None } \\
\hline $982 \mathrm{Ar}+2.9 \% \mathrm{H}_{2}$ & 0 & & & $\mathrm{Ar}+2.9 \% \mathrm{H} 2$ & \\
\hline 982 Air & $\overline{0}$ & & & Air & \\
\hline $1093 \mathrm{Ar}+2.9 \% \mathrm{H} 2$ & 0 & & & $\mathrm{Ar}+2.9 \% \mathrm{H} 2$ & \\
\hline $982 \mathrm{Ar}+2.9 \% \mathrm{H} 2$ & 0 & & & $\mathrm{Ar}+2.9 \% \mathrm{H} 2$ & \\
\hline None & None & 871 & 0.8 & Air & $2 \operatorname{Min} T$ \\
\hline \multirow[t]{4}{*}{ None } & \multirow[t]{4}{*}{ None } & \multirow[t]{4}{*}{1038} & \multirow[t]{4}{*}{0.8} & Air & $2 \operatorname{Min} C$ \\
\hline & & & & $\mathrm{Ar}+2.9 \% \mathrm{H}_{2}$ & $2 \operatorname{Min} C$ \\
\hline & & & & Air & $2 \operatorname{Min} T$ \\
\hline & & & & $\mathrm{Ar}+2.9 \% \mathrm{H}_{2}$ & $2 \operatorname{Min} T$ \\
\hline
\end{tabular}

$R_{\varepsilon}=-1$, Strain Rate $=0.5 \% / \mathrm{s}, 100$ hour pre-exposure

Table 3.1.2 Fatigue Damage Tests

\begin{tabular}{|c|c|c|c|}
\hline $\begin{array}{c}\text { Temperature } \\
\left({ }^{\circ} \mathrm{C}\right)\end{array}$ & $\begin{array}{c}\text { Strain Rate } \\
(\% / \mathrm{s})\end{array}$ & $\begin{array}{c}\text { Strain Range } \\
\Delta \varepsilon_{m}(\%)\end{array}$ & $\begin{array}{c}\text { Strain Ratio } \\
R_{\varepsilon}\end{array}$ \\
\hline 760 & 0.5 & 1 & -1 \\
\hline & & 0.5 & -1 \\
\hline \multirow{2}{*}{871} & \multirow{2}{*}{0.5} & 1.5 & 0 \\
\cline { 3 - 4 } & & 1 & 0 \\
\cline { 3 - 4 } & & 0.8 & 0 \\
\cline { 3 - 4 } & & 2 & -1 \\
\cline { 3 - 4 } & & 0.9 & -1 \\
\hline 927 & 0.5 & 0.8 & -1 \\
\hline
\end{tabular}

In addition to the samples that will be isothermally tested, some will be subjected to superimposed thermal and mechanical cycling as listed in Table 3.1.3. Additional stress-free experiments are also needed to complete the development of the surface layer ingression models. Observations from samples tested at $927^{\circ} \mathrm{C}$ and $1093^{\circ} \mathrm{C}$ will be used to complement the existing data set containing $871^{\circ} \mathrm{C}, 982^{\circ} \mathrm{C}$, and $1038^{\circ} \mathrm{C}$ measurements. Parameters will be identified to 
develop mechanistic models that correlate the microstructural state to test condition and residual life.

Table 3.1.3 Oxidation-Fatigue Damage Tests

\begin{tabular}{|c|c|c|c|}
\hline \multirow{2}{*}{ Temperature $\left({ }^{\circ} \mathrm{C}\right)$} & Hold Type & $\begin{array}{c}\text { Strain } \\
\text { Range } \Delta \varepsilon_{m} \\
(\%)\end{array}$ & $\begin{array}{c}\text { Strain Ratio } \\
R_{\varepsilon}\end{array}$ \\
\hline $538-1038(\mathrm{OP})$ & None & 0.5 & -1 \\
\cline { 3 - 4 } & & 1 & -1 \\
\hline $538-1038(\mathrm{IP})$ & None & 0.5 & -1 \\
\cline { 3 - 4 } $538-927(\mathrm{IP})$ & & 1 & -1 \\
\hline 1038 & $10 \mathrm{Min} \mathrm{C}$ & 1 & -1 \\
\cline { 3 - 4 } & $10 \mathrm{Min} \mathrm{T}$ & 1 & -1 \\
\hline
\end{tabular}

Since DS Ni-base superalloys exhibit considerable resistance to diffusional degradation, creep damage is the least prominent of the three mechanisms. In some instances, the damage inflicted by creep mechanisms are shielded by the remaining damage forms. For example, isothermal testing conditions having a high plastic strain rate, crack initiation is dominated by fatigue, whereas tests with low plastic strain rates are dominated by environment. One way to separate the contributions of environmental damage from creep damage is by performing tests in a nonoxidizing atmosphere. The test arrangement used for isothermal and TMF tests will be modified to surround the specimen gage section in a flowing two component gas mixture $\left(\mathrm{Ar}+2.9 \% \mathrm{H}_{2}\right)$. This will require the fabrication of a semi-closed chamber to partially house the specimen, induction coils, and extensometer tips, which is shown in Fig. 3.1.1. The list of supplies needed to conduct the alternate environment experiments have been finalized:

- $\quad$ Lexan ${ }^{\circledR}$ glass tubing

- Zirconium-based oxygen sensor

- $\quad$ Two component gas mixture $\left(\mathrm{Ar}+2.9 \% \mathrm{H}_{2}\right)$

- Gas regulator

- $\quad$ Silicone sealant

- $\quad$ Swagelok tubing, fittings, and lubricants

The oxygen probe will be mounted within the chamber to quantify the partial pressure of oxygen, $P_{\mathrm{O}_{2}}$, contained in the environment. Based on the preliminary tests, cavitation and subsurface microcrack were observed with tests having hold times. Several of these tests, described in Tables 3.1.1-3, will be repeated in the non-oxidizing environments. Comparing microstructures from preliminary and new tests will directly indicate the interaction between environment and creep damage. Using Batch 3 specimens, the two-phase testing program given in Table 3.1.1, has commenced. 


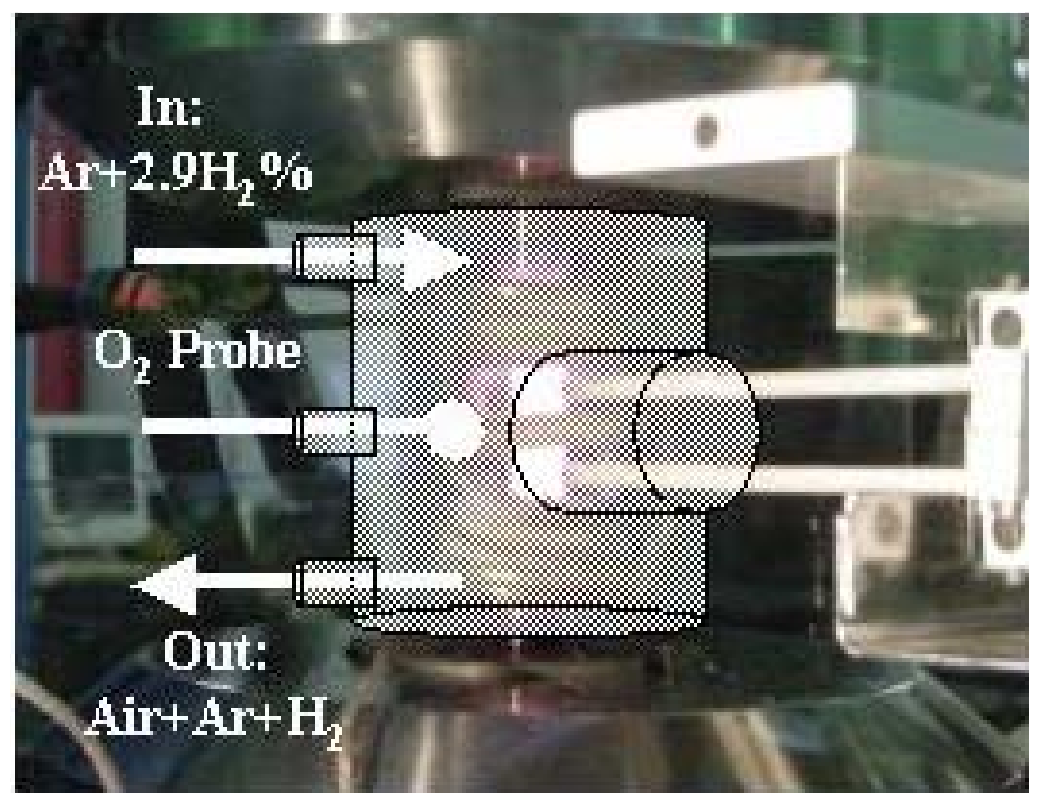

Figure 3.1.1 Lexan ${ }^{\circledR}$ chamber to be fabricated for use with inert gas experiments

\section{TGA investigation}

The stress-free interdendritic oxidation and sulfidation kinetics of DS GTD-111 will compared using thermogravimetric analysis (TGA) which has been configured with a gas mixing system and Cahn microbalance. Table 3.1.4 summarizes the tests that will be conducted in the TGA. There are a total of 20 tests; 16 GE GTD-111 DS samples and 4 homogenized samples. The resulting oxide/sulfide scales will be examined using EDS and EBSD and compared to the results of the isothermal tests.

Table 3.1.4 TGA Tests

\begin{tabular}{|c|c|c|c|c|}
\hline Temperature & \multicolumn{5}{|c|}{ Environment } \\
\hline $\begin{array}{c}\text { Time }= \\
100 \text { Hours }\end{array}$ & $\begin{array}{c}\text { Airt } \\
\mathrm{H}_{2} \mathrm{O}\end{array}$ & $\begin{array}{c}\text { Dry } \\
\text { Air }\end{array}$ & $\begin{array}{c}\mathrm{N}_{2}+100 \mathrm{pp} \\
\mathrm{m} \mathrm{H}_{2} \mathrm{~S}\end{array}$ & $\begin{array}{c}\mathrm{N}_{2}+100 \mathrm{pp} \\
\mathrm{m} \mathrm{H}_{2} \mathrm{~S}\end{array}$ \\
\hline $\begin{array}{c}1400 \mathrm{~F} \\
(760 \mathrm{C})\end{array}$ & $1 \mathrm{a}$ & $2 \mathrm{a}$ & $3 \mathrm{a}$ & $4 \mathrm{a}$ \\
\hline $\begin{array}{c}1600 \mathrm{~F} \\
(871)\end{array}$ & $1 \mathrm{~b}$ & $2 \mathrm{~b}$ & $3 \mathrm{~b}$ & $4 \mathrm{~b}$ \\
\hline $\begin{array}{c}1900 \mathrm{~F} \\
(1038 \mathrm{C})\end{array}$ & $1 \mathrm{c}$ & $2 \mathrm{c}$ & $3 \mathrm{c}$ & $4 \mathrm{c}$ \\
\hline
\end{tabular}

Additional tests using homogenized samples

More details concerning the experimental method is described in a $\mathrm{PhD}$ proposal (Trexler, 2004). The results that are obtained from these experiments will be useful in developing a transfer function relating the exposure history to residual life. 


\section{Task 2: Material In-Service Health Monitoring:}

This report covers sensor requirements for Coal IGCC gas turbines, sensor capability studies, improved analytical methods, and sensor field testing.

Subtask 2.2 is developing a sensor system to rapidly and accurately determine Syngas fuel quality and lower heating value (LHV). Sandia National Lab has continued the basic development of the sensor, while the overall system development has continued at GE Global Research Center. Optimization and calibration of the LHV sensor were continued during this reporting period with field tests being conducted at Southern Company Power Systems Development Facility (PSDF) facility in Wilsonville, AL.

Subtask 2.3 is developing methods to measure thermal variation of gas turbine parts using IR pyrometers and IR cameras. Pyrometer software was installed for monitoring and reporting the condition of Stage 1 turbine buckets in operating machines. The methodology of predicting temperature of the buckets is being improved using updated analysis tools, and a methodology to determine and report the condition of the buckets in real time has been developed. Pyrometers were re-commissioned on the Cinergy/PSI Wabash River Station GE 7FA IGCC gas turbine, and the Stage 1 buckets were inspected on the Duke Energy Moss Landing GE 7FA+e gas turbine.

\section{Subtask 2.2 - Sensor Capability Studies:}

\section{Fuel Lower Heating Value (LHV) Sensor}

Gaseous fuel used in reciprocating and gas turbine engines can experience significant variations in its heating value, which can affect their performance. In particular, Coal gasification produced Syngas fuel quality can adversely effect engine performance. Additionally the reciprocating engines at GE Jenbacher commonly use special fuels that contain bio-gas and waste gases, which can produce substantial changes in a short time period. Hence, subtask 2.2 is concentrated on a sensor design to accurately determine the lower heating value (LHV) rapidly.

As part of the DOE Smart Turbine Program, Sandia National Laboratory developed a prototype sensor that could be used to measure the LHV. This device uses a pair of micro hot plates, which are MEMS chips that can produce a uniform temperature across their surface. A catalytic material was applied to one of the chips that combusts a fuel/air mixture passed over its surface. Since the hotplate is maintained at a constant temperature, a lower power is required with the combustion energy release. The second hotplate is used to measure the convective heat transfer due to the fluid flow. The overall change in the power supplied to these two chips is a directly related to the LHV. The time response of the micro hot plates is on the order of milliseconds, so the heating value could be measured nearly in real time.

\section{Gas Chromatography on Combustion Products}

A gas chromatography (GC) system (Agilent 3000 MicroGC) is being used to study exhaust from the LHV sensor rig. The purpose of these experiments is to better correlate LHV sensor signal with BTU content of the fuel, understand combustion in the sensor rig, and determine the combustion efficiencies of fuel constituents. The testing will ultimately encompass four different natural gas standards, several singular natural gas components, and Syngas mixtures (once appropriate standards have been located). 
The GC system was calibrated for all components expected in testing. Calibration resulted in linear signal response for $\mathrm{C} 1-\mathrm{C} 5$, nitrogen, oxygen, carbon dioxide, carbon monoxide, and hydrogen over a wide range of concentrations. Water was difficult to measure given the lack of heat tracing on the sample lines, however a calibration for it was still developed. In addition to signal linearity, the GC system shows a reasonable noise floor and signal repeatability. Prior to the combustion studies, modifications were made to the LHV sensor rig that would allow for both pre-combustion and post-combustion sampling of the air/fuel stream. The experimental procedure would entail pre-combustion sampling from this mixture to establish a baseline, followed by post-combustion sampling to record the affects of the catalytic combustion. Unless otherwise noted, the conditions for the following experiments were identical with the LHV sensor temperature set to $480^{\circ} \mathrm{C}$, and the air/fuel flow rate at $40 \mathrm{sccm}$.

\section{Laboratory-based Testing Stations}

Lab based testing stations expanded with two additional MKS 1179A mass flow controllers (MFCs). Thus there are three MFCs for fuel gases and one for air. With this setup, as shown in Figure 3.2.1, it is possible to generate mixtures of gases, for instance, simulating Syngas. Additionally this gives the capability to perform sweeps in LHV and monitor the sensor output by varying the gas mixture.

One additional testing station has been added. The lab at GE Global Research now consists of two full testing stations, each with four MFCs. This second station has been commissioned and is awaiting final health and safety approval to run unattended. Continual running of the sensor allows reliability testing of the sensor over the long term. One of the stations is left to run continually at a fixed condition to examine the sensor response with time.

\section{Orifice Flow Control}

MFCs are ideal for use in the laboratory because they precisely control the flow of a known gas. However, in the field, the sensor must respond to the fuel gas that is present. Here, the goal is to control the mass flow of that gas and to balance it versus the flow of air to achieve a particular fuel to air ratio. Additionally, the flow control device must be adequate for high temperature fuels (up to $200^{\circ} \mathrm{C}$ ) and fuels with contaminants (particulates, tars, etc). The lowest cost and most robust solution is choked flow through an orifice.

If the pressure upstream of an orifice is sufficiently higher than the pressure downstream, the velocity of the gas flowing through the orifice will be constant. This flow is said to be "choked." It is possible to have changes in mass flow if the density of the gas changes. However the amount of variation in mass flow is easily calculated given a gas's density and choked flow. For this reason, and its relative low cost with respect to that of an MFC, an orifice was chosen to control the gas flow through the sensor.

For the field tests performed, the fuel gases being measured were known to vary within certain limits. An orifice was chosen such that the flows allowed over those limits would be sufficient for sensor operation. 


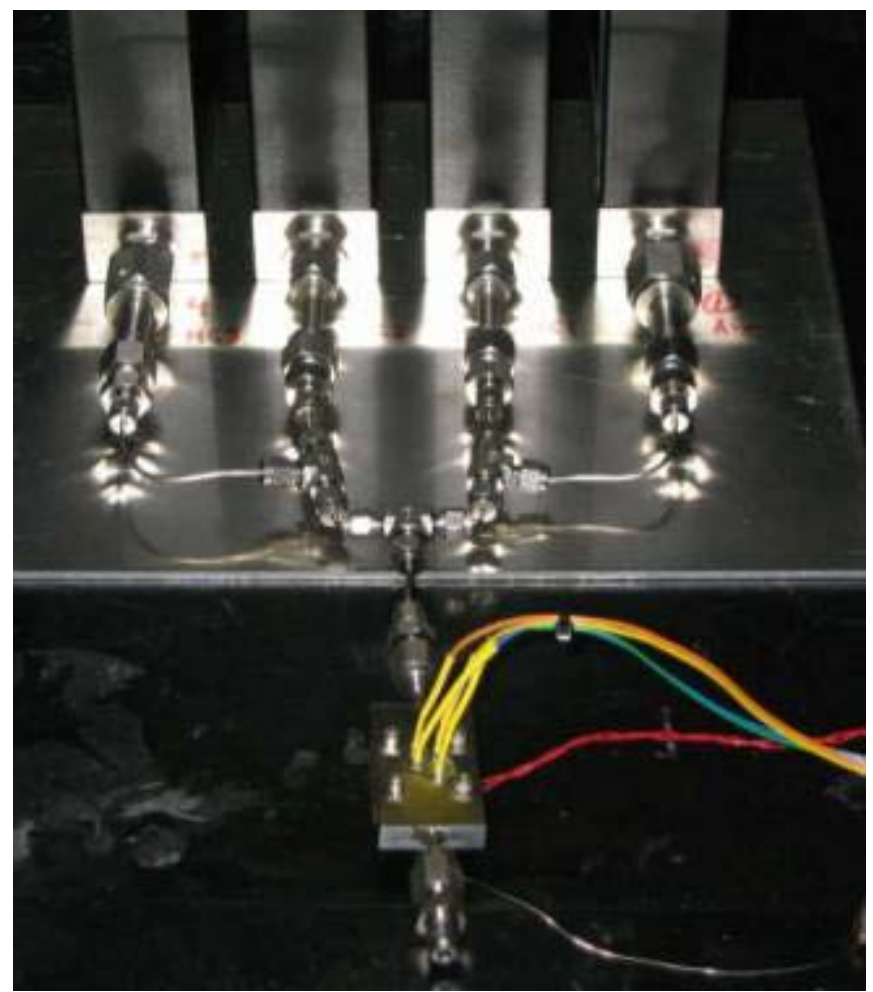

Figure 3.2.1 Laboratory based testing station showing four mass flow controllers (MFCs) at the top and piping leading to the LHV sensor

\section{Optimization of Sensor Parameters for Syngas Fuels}

A number of tests were run to find optimum values of fuel to air ratio and flow rates such that the LHV sensor could be used to measure Syngas fuels. It was not possible to obtain samples of actual Syngas to measure in a laboratory environment. However, data was obtained that contained the typical constituents present in Syngas. From these data, the concentrations of the major gas constituents present (e.g. $\mathrm{H}_{2}, \mathrm{CO}$, and $\mathrm{CH}_{4}$ ) were used in these tests. These gases were mixed to the concentrations typically seen in Syngas fuels using MFCs. The results of these test runs were the optimum flow rate and fuel to air ratio to be used during field tests.

\section{Subtask 2.3 - IR Pyrometer for Condition Based Maintenance:}

The specific tasks include:

1. Pre-determining the thermal variation of the buckets

2. Monitoring the pyrometer data at Duke Maine Independence and Duke Moss Landing

3. Commissioning the pyrometers on the Wabash River Station 7FA IGCC gas turbine

4. Inspecting the Stage 1 buckets on the Duke Moss Landing 7FA+e gas turbine

5. Correlating the inspection data with pyrometer data and thermal image data

6. Improving the methodology to predict temperature of the buckets

7. Developing a methodology to determine condition of the buckets

8. Developing a strategy for bucket reliability management 


\section{Pre-determining the Thermal Variation of the Buckets}

This methodology was described in the semi-annual report for the period March - August 2003.

\section{Pyrometer Monitoring Software}

Software has been implemented on the pyrometer data acquisition computer to communicate any errors encountered to the gas turbine's on-site monitoring (OSM) system. These errors are then routed to the GE Energy Remote Monitoring and Diagnostics (RM\&D) center in Atlanta, GA. There are two classes of errors reported: anomalies with the pyrometer hardware and anomalies with the gas turbine buckets.

\section{Re-commissioning the pyrometers at the Cinergy/PSI Wabash River Station}

The Cinergy/PSI Wabash River Station 7FA IGCC gas turbine has five pyrometers mounted to monitor on all three stages of the turbine. Figure 3.2.2 shows photographs of the turbine with the locations of the pyrometers.

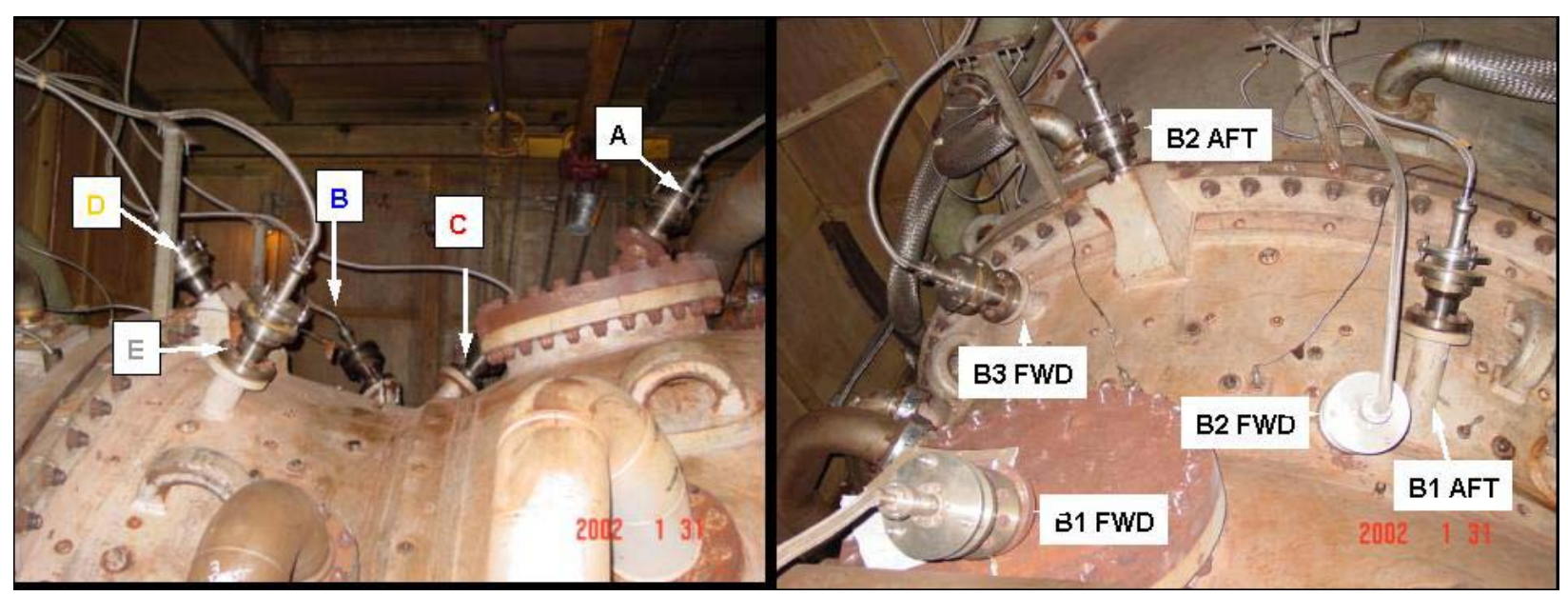

Figure 3.2.2 Five pyrometers on the PSI-Cinergy Wabash River 7FA gas turbine: Pyrometer A: B1FWD - monitors Stage 1 buckets from forward Pyrometer B: B1AFT - monitors Stage 1 buckets from aft Pyrometer C: B2FWD - monitors Stage 2 buckets from forward Pyrometer D: B2AFT - monitors Stage 2 buckets from aft Pyrometer E: B3FWD - monitors Stage 2 buckets from forward

The 5 pyrometer fiber optic light guides and alignment flanges at the site had been removed for a combustion inspection. The following tasks were performed:

- Pyrometer calibration checked and adjusted

- Alignment flanges re-installed and aligned

- GRC computer connectivity to GE network re-established

- Pyrometer connectivity to data acquisition systems confirmed

- Bucket indexing performed 


\section{Pyrometer calibration}

The pyrometers were calibrated before and after cleaning of the quartz windows at a furnace temperature of $960^{\circ} \mathrm{C}$.

\section{Pyrometer alignment}

The pyrometer alignment flanges were re-installed by on-site mechanics. Alignment of each of the stages was performed. As is normally done, the flanges were aligned such that the pyrometer field of view is centered on the end of the site tube.

\section{Pyrometer computer connectivity}

The Wabash River site remains a dial-up site. Prior to the visit, the Atlanta RM\&D center was experiencing difficulties in connecting to the on-site monitoring system. This problem has been resolved.

\section{Bucket Indexing}

Each of the 5 pyrometers (Stage 1 pressure/suction, Stage 2 pressure/suction, Stage 3 pressure) were videoed via a boroscope as the rotor was hand cranked. Additionally, the key phaser (KP) signal was monitored, thus enabling the video to be synchronized to the firing of the KP. The objective was to correlate the pyrometer data with observed bucket condition.

\section{Improving the Methodology to Predict Temperature of the Buckets}

The pyrometer field of view is small compared with the total surface area of the gas turbine buckets. In order to extend the real time temperature measurements to the entire bucket, a UniGraphics LOS utility has been developed to rapidly transfer the pyrometer measurements to a finite element model of the bucket. The flow chart of the utility illustrated in Figure 3.2.3.

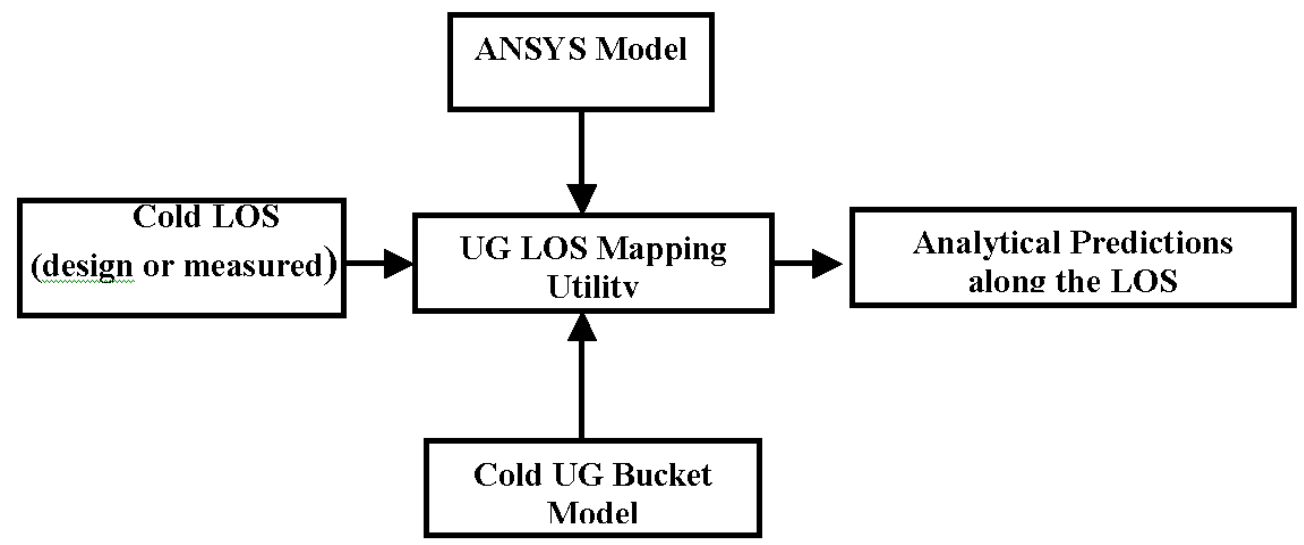

Figure 3.2.3 UG utility flow chart 
As a result of the validation work, several critical modifications to the code were identified:

- Additional user input required to utilize the mouse click LOS definition option

- Modify code logic to improve the extraction of temperature predictions from the ANSYS solution

- Increase the number of characters accepted in GUI interface to accommodate longer path names

- Upgrade the code logic utility to accommodate either (1) or (2) shadow geometric configurations

The upgraded UG LOS utility has been completed and comparisons of optical pyrometer temperature measurements to analytical predictions are underway.

\section{Methodology to Determine Condition of the Buckets}

As part of the long-term IR pyrometer data collection from the Duke Energy gas turbines (Moss Landing and Maine Independence powerplants), a boroscope inspection was performed at the Moss Landing plant during their Combustion Inspection outage in June. Two main tasks were accomplished during this inspection: 1) routine pyrometer maintenance and 2) visual inspection of the Stage 1 buckets via boroscope for comparison with pyrometer and thermal imaging data.

\section{Subtask 2.4 - Field Deployment and System Validation:}

\section{Syngas Field Test of the LHV Sensor}

The sensor was extensively operated on Syngas fuels during a field test at the Power Systems Development Facility (PSDF), located in Wilsonville, AL. This is a Department of Energy funded site administrated by Southern Company, and consists of a small-scale gasifier that is used to test different processes of Syngas production. Given its research and development role, the entire process is more heavily instrumented than a commercial Coal IGCC plant. This includes a number of gas chromatographs (GC) measuring the fuel stream constituents, from which an independent value of the LHV was obtained. The PSDF provided a unique environment in which to test the LHV sensor, as the supplementary data was needed to fully evaluate and interpret the sensor's performance with a Syngas fuel stream.

The testing had two main goals: 1) evaluation of the reliability of the sensor and 2) evaluation of the accuracy of the sensor output versus that of the GCs. The test was conducted over five days using two different gas streams, during both $\mathrm{O}_{2}$-blown and Air-blown gasifier operation. The first was a low temperature $\left(65.5^{\circ} \mathrm{C}\right)$ gas stream, which had passed through a series of condensing tanks to remove a significant portion of the water vapor and contaminants present in the raw, unconditioned gas stream. The second was a high temperature $\left(260^{\circ} \mathrm{C}\right)$ gas stream from sampling the raw Syngas. As the gas was passed through the sensor it was further reduced in temperature to $176.7^{\circ} \mathrm{C}$. Orifices and choked flow were used to regulate the mass flow through the sensor during all tests. The fixture and flow control hardware is shown in Figure 3.2.4. 


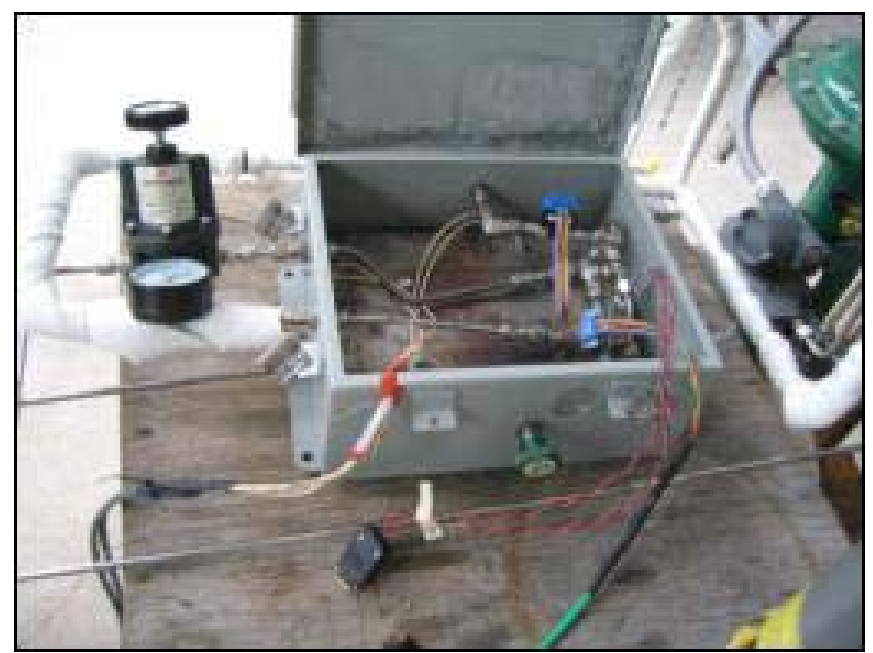

Figure 3.2.4 Sensor fixture with orifices and related plumbing. The setup shown above is for the measurement of Syngas and is capable of internal temperatures of up to $170^{\circ} \mathrm{C}$. 


\subsection{Results and Discussion}

The program status results are presented on a separate Task basis, as each of the Tasks address separate areas of effort. Detailed task results are discussed for each active subtasks, as appropriate, for activities during this reporting period. An overview section has been included to clarify each task's (and sub-task's) intentions, and aid the understanding of progress to date.

\section{Task 1 Status/Discussion:}

Overview: This report details progress for Task 1, IGCC Environmental Impact on High Temperature Materials. The contributors to Task 1 are the GE Global Research Center, Georgia Institute of Technology, and GE Energy. This task has been divided into the two following subtasks:

Subtask 1.1 - High Temperature Erosion/Corrosion Data Collection

The high temperature erosion and corrosion behavior of a wide variety of materials commonly used in gas turbine buckets, nozzles, and combustor hardware will be characterized. Laboratory erosion and corrosion experiments at elevated temperatures will be conducted in order to document the environmental effects associated with a Coal IGCC application. Corrosion kinetics will be recorded as well as the corrosion product morphology evolution as a function of time, temperature and gas environment. Erosion experiments will be conducted at elevated temperatures and the effect of foreign object impact on coatings and native corrosion scales will be documented. Mechanical properties experiments will be conducted on alloys exposed to erosive and corrosive environments. Fuel and exhaust gas sampling will be performed at one or more Coal IGCC powerplants to develop correlations between the Syngas composition and gasifier / gas turbine load level. Additionally, combustor and hot gas path (HGP) parts will be removed from a Coal IGCC power plant for evaluation as part availability permits. The condition of the parts removed from service will be documented in order to correlate to the fuel sampling being conducted.

Subtask 1.2 - High Temperature Erosion/Corrosion Mechanism Quantification

Using the data collected in subtask 1.1 along with micro-structural analysis of virgin materials and service-exposed materials, scale growth mechanisms and erosion effects will be determined by comparing to a control. Corrosion scale product will be determined along with growth kinetics. Corrosion scale growth and failure will be quantified. The effect of erosion on coating performance will be determined. Foreign object impact failure mechanism will be determined. The effect of environmental exposure (erosion and/or corrosion) on mechanical properties will be quantified. 


\section{$\underline{\text { Task } 1 \text { Discussion: }}$}

Sub-Task 1.1 - High Temperature Erosion/Corrosion Data Collection:

\section{Syngas Sampling}

Syngas fuel sampling tests were performed on June 5-7, 2004 at the Tampa Electric Company (TECo) Polk 1 powerplant, located near Mulberry, FL. The purpose of the fuel sampling was to evaluate the effect of Syngas fuel constituents and contaminants on the service lives of gas turbine combustion and downstream turbine components during actual operating conditions. Cubix Corporation sampled for combustible gases, particulate matter (PM), metals, $\mathrm{HCl}$, Ammonia $\left(\mathrm{NH}_{3}\right)$, and sulfur species at two locations on the Syngas fuel line to the GE MS7001F IGCC gas turbine. Three test runs were performed simultaneously at each location: prefilter and post-filter. The first two runs were performed during startup of the gas turbine. The third run was performed when the turbine was at full load. A total of six Syngas samples were taken. Syngas fuel residue samples were taken from the Syngas fuel filter and gas turbine fuel strainer during gasifier/gas turbine shutdown.

The sampling results are given in Tables 4.1.1-3 Table 4.1.1 provides the results at Location 1 (pre-filter). Table 4.1.2 provides the results at Location 2 (post-filter). Table 4.1 .3 provides the qualitative results of the strainer rinse. On the summary of results tables, particulate matter data during runs 1 and 2 is presented in duplicate.

\section{Characterization of Serviced Parts}

TECo provided two Stage 1 buckets and two Stage 2 buckets for analysis. The service conditions are described in Table 4.1.4.

Preliminary microscopic analysis was performed on the leading edge of one of the Stage 1 buckets (directionally solidified GTD-111 + CoCrAlY coating with over-aluminide). At the leading edge of the bucket, two distinct surface reactions were observed. Figure 4.1.1 shows the cross-section of the surface at one region on the bucket. The surface reaction is what is commonly observed in a high temperature oxidizing environment, typical for hot gas path parts in gas turbines fired by natural gas. Figure 4.1.2 shows the cross-section of the surface of the Stage 1 bucket at a different area of the leading edge. The surface reaction in this case is radically different from what is typically observed on the surface of hot gas path parts in gas turbines fired by natural gas. Figure 4.1.3 is a higher magnification of the same area depicted in figure 4.1.2. Noted on the photomicrograph the presence of sulfides and the absence of a continuous alumina layer. 
Table 4.1.1 Summary of Results at Syngas Location 1 (Pre-filter)

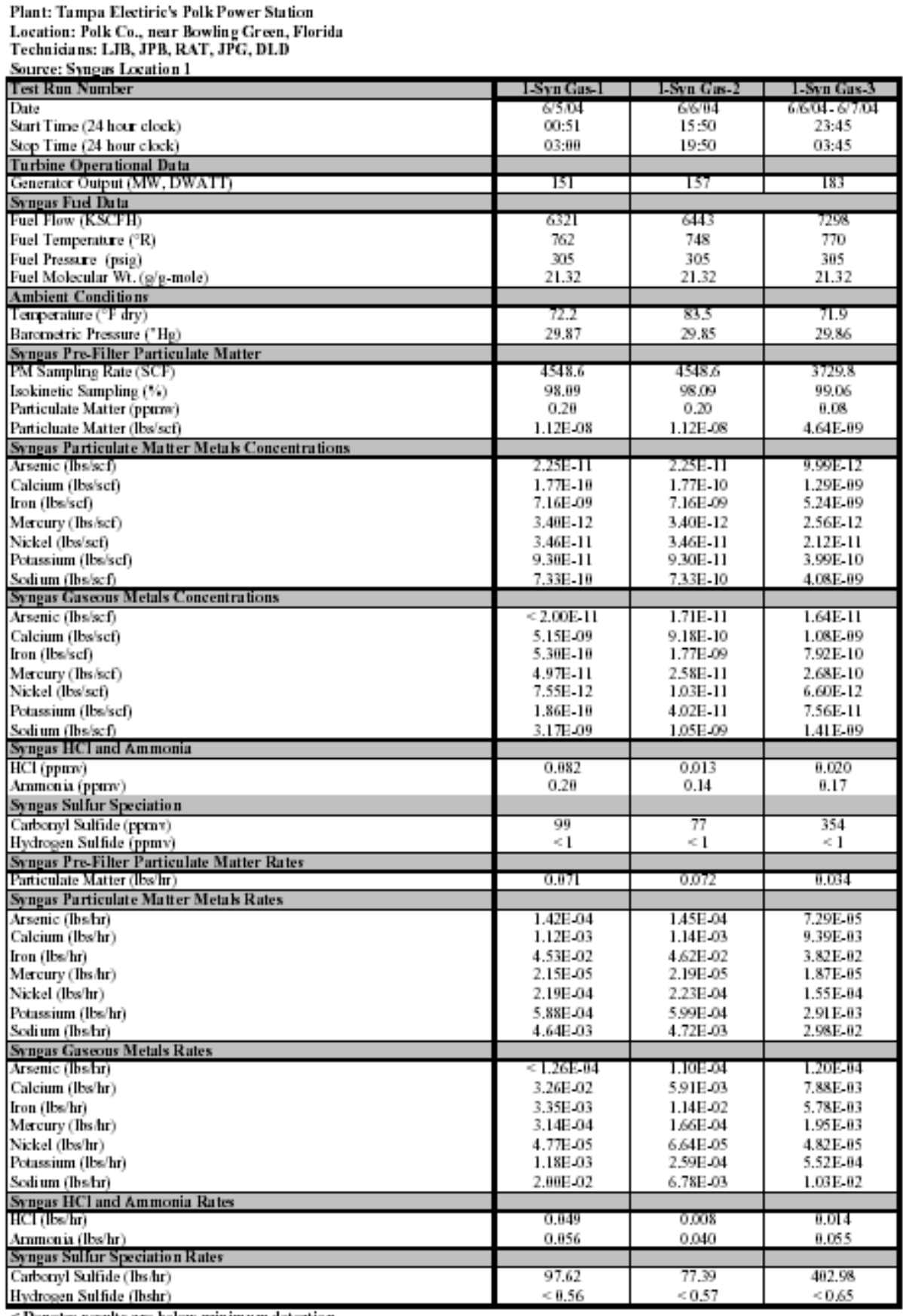

$<$ Denoles results are below minimum detextion

Testing by Cubix Corporation -Gainesville, Flerida 
Table 4.1.2 Summary of Results at Syngas Location 2 (Post-filter)

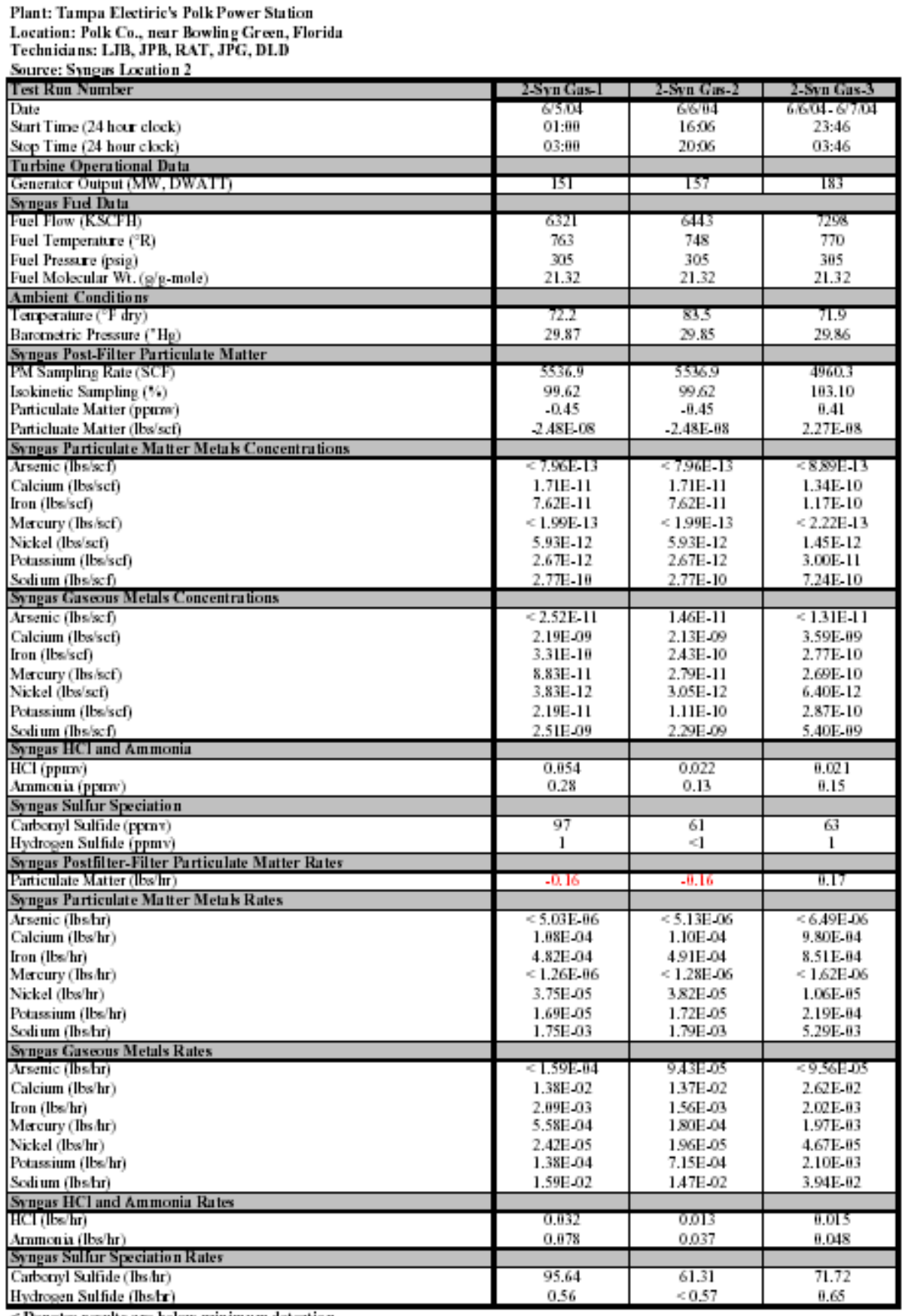

$<$ Denotes results are below minimum detestion

Testing by Cubix Corporaticn - Gainesrille, Florida 
Table 4.1.3 Summary of Results for Strainer Rinse

\begin{tabular}{|lc|}
\hline Analyte & Results ( $\mu$ g/sample) \\
\hline $\mathrm{Cl}$ & 358 \\
$\mathrm{NO}_{3}$ & 36,800 \\
$\mathrm{SO}_{4}$ & 6,620 \\
Antimony & 15.3 \\
Arsenic & 60.4 \\
Barium & 10.8 \\
Beryllium & 4.48 \\
Cadmium & 14.7 \\
Calcium & 1,570 \\
Chromium & 1,040 \\
Cobalt & 24.3 \\
Copper & 70.1 \\
Iron & 65,400 \\
Lead & 3.12 \\
Manganese & 981 \\
Mercury & $<$ MDL $(0.51)$ \\
Nickle & 801 \\
Phosphorus & 128 \\
Potassium & 393 \\
Selenium & 535 \\
Silver & $<$ MDL $(0.26)$ \\
Sodium & 1970 \\
Thallium & 5.78 \\
Zink & 242 \\
\hline
\end{tabular}

Table 4.1.4 Service conditions for the Stage 1 and two Stage 2 buckets provided by TECo

\begin{tabular}{|l|l|}
\hline Customer & TECO-Polk County \\
\hline Machine Type (Model Series) & MS7221FA \\
\hline Turbine S/N & 296436 \\
\hline Steam/Water Injection & $0 \%$ \\
\hline Fuel Type & Syngas and \#2 distillate \\
\hline Plant Type & IGCC \\
\hline Fired Starts & 238 \\
\hline Emergency Trips & 117 \\
\hline Total Fired Hours & 22975 \\
\hline Base Load Fired Hours & 22975 \\
\hline
\end{tabular}




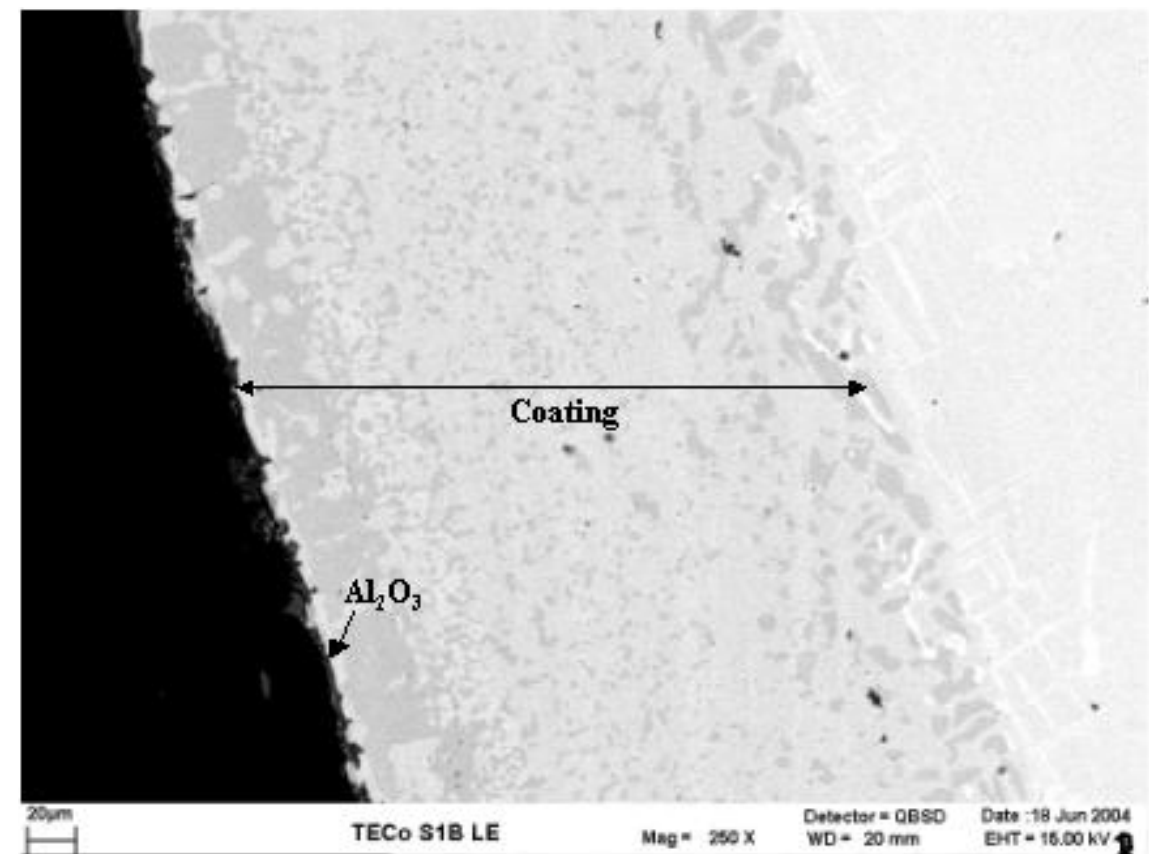

Figure 4.1.1 Cross section of Stage 1 bucket leading edge showing typical high temperature oxidizing surface reactions

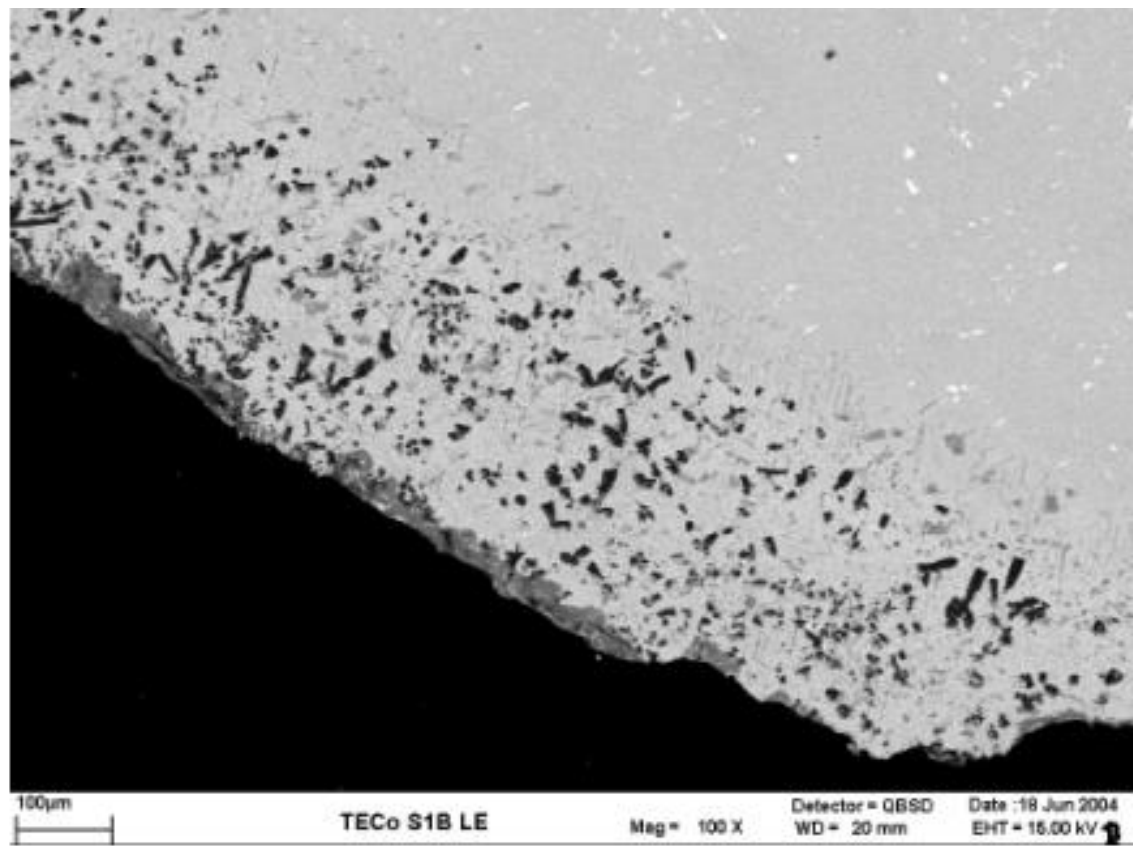

Figure 4.1.2 Cross section of Stage 1 bucket leading edge showing atypical surface reactions (see Fig. 4.1.3) 


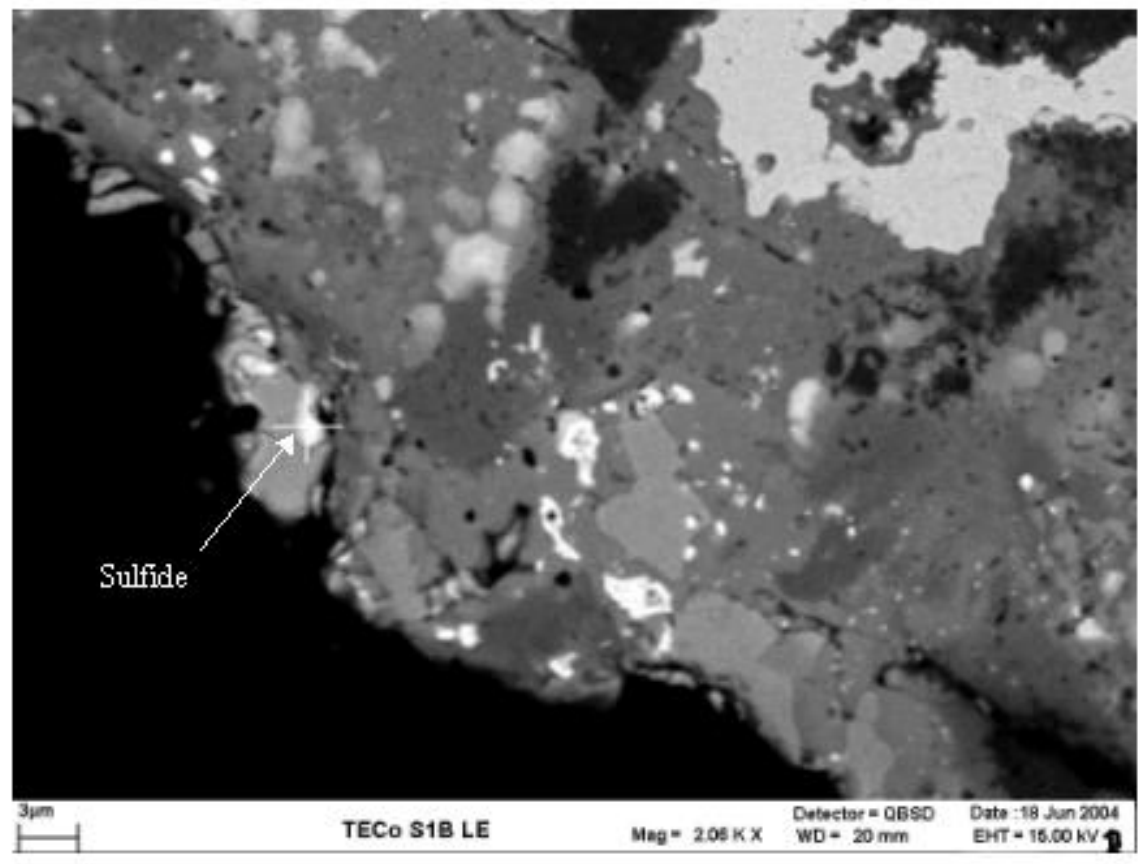

Figure 4.1.3 Higher magnification of the same area depicted in figure 4.1.2. Note the presence of sulfides and the absence of a continuous alumina layer.

\section{High Temperature Corrosion Study}

Characterization of unstressed microstructure with environmental exposure

Isothermal exposures of stress-free coupon sample discs were conducted. The values of oxidation penetration depth, $L_{O X}$, and $\gamma^{\prime}$-depletion, $L_{\gamma^{\prime}}$, reported are the averages of several direct measurements from multiple locations of micrographs of samples and compared to a virgin, exposed sample. The data indicates history-dependent oxidation accumulation. Specimens subjected to longer exposure times and/or higher temperatures displayed an increased depth in oxide formation, as shown in Fig. 4.1.4.
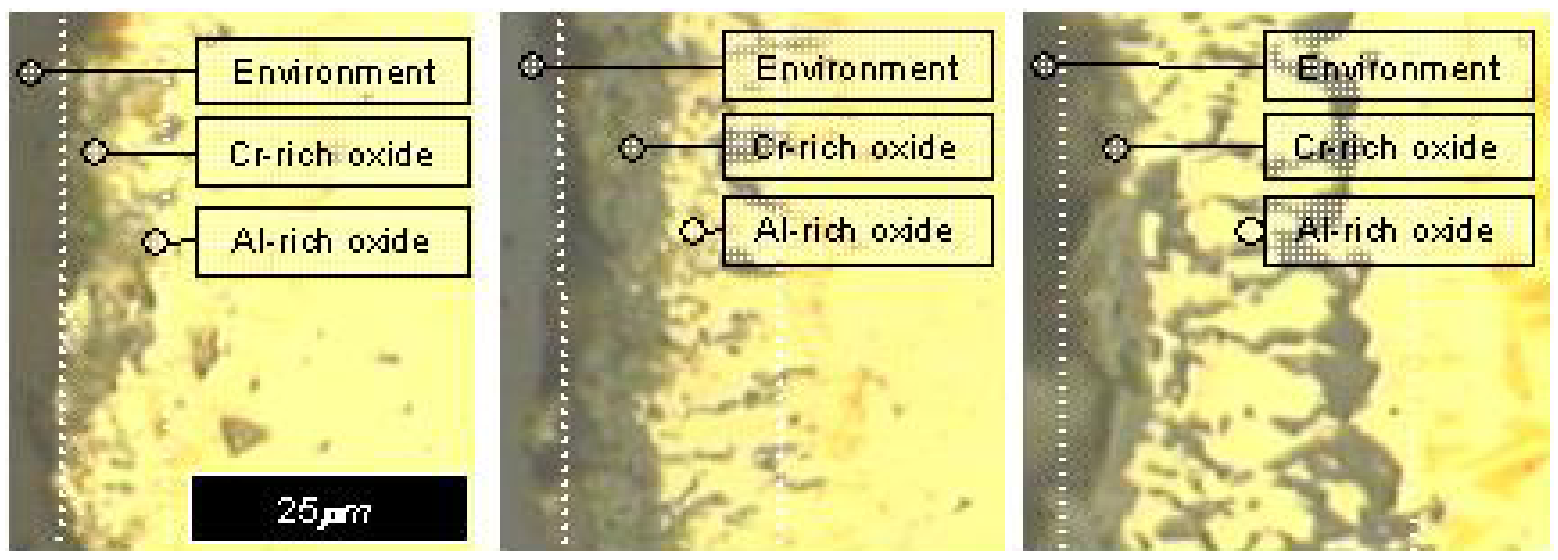

Figure 4.1.4 Surface oxidation observed in an unstressed DS GTD-111. Specimens were subjected to $1038^{\circ} \mathrm{C}\left(1900^{\circ} \mathrm{F}\right)$ for (left) $3.2 \mathrm{hr}$, (middle) $31.6 \mathrm{hr}$, and (right) $316 \mathrm{hr}$. 
The accumulated oxidation layer consists of several distinct layers. The outer layer is a homogeneous mixture of $\mathrm{Ti}$ - and Cr-rich oxides, while the inner layer is Al-rich and intermingled with matrix material. As the reaction proceeded at a constant rate, the increase in scale layer thickness resulted in a reduction in metal diffusion across the scale and, consequently, to a reduction in the reaction rate. In other words, after an initial oxidation scale develops, one or more of the reactants must be transported across the accumulated scale for the oxidation process to continue. The initial transient and subsequent steady state oxidation accumulation stages were correlated using a quartic law:

$$
L_{O X}=\alpha_{O X} f\left(\sigma_{m}, \Delta \varepsilon_{i n}\right)\left[\Theta_{O X}(T) t\right]^{\frac{1}{4}}
$$

We define $f$ as a factor that accounts for oxidation enhancement resulting from mechanical loading. This factor will explicitly be determined with the analysis of mechanically loaded specimens; however, under unstressed conditions, $f=1$. An evolution model was also developed for $\gamma^{\prime}$-depletion by replicating the procedure for determination of the oxidation model. Precipitate depletion depths were generally larger than oxidation depths; however, the presence of two diffusion stages (transient and steady state) was identical. The quartic formulation given in Eq. (1) correlates matrix layer evolution well, i.e.

$$
L_{G P D}=\alpha_{G P D} f\left(\sigma_{m}, \Delta \varepsilon_{i n}\right)\left[\Theta_{G P D}(T) t\right]^{\frac{1}{4}}
$$

These relations which model the initial interdenditic oxidation connections of DS GTD-111, will be used in the development of the environmental damage term in the crack initiation model. This term will account for the effect of repeated rupture and oxidation of surface layers on crack initiation.

Below $950^{\circ} \mathrm{C}$, the compositions of the surface oxides are dominantly $\mathrm{Cr}$ and Ti-rich, whereas above this temperature, the oxides are rich with Al. Alumina, $\mathrm{Al}_{2} \mathrm{O}_{3}$, has the best overall protective properties due to its high thermodynamic stability, its slow growth rate, and its adherence to the substrate. As a result, oxidation rates in Ni-base superalloys are largely dependent on the $\mathrm{Cr}, \mathrm{Ti}$, and Al-content. Since the different reactants in the alloy have varied affinities for oxygen, reflected by the different free energies of formation of the oxides, the various metal ions will have different mobilities in the various oxide phases; hence, the oxidation process in alloys is much more complex than in pure metals. Surface-grown alumina causes the smallest change to surface geometry, while in $\mathrm{Cr} / \mathrm{Ti}$-oxides, large compressive stresses leading to buckling and spalling are likely to occur.

\section{Sub-Task 1.2 - High Temperature Erosion/Corrosion Mechanism Quantification:}

TECo has provided serviced hot gas path parts for microscopic analysis. The preliminary analysis of a Stage 1 bucket has indicated that the environment the part encountered altered the corrosion product on the surface. In some areas, the coating microstructure and composition indicated typical oxidation behavior seen in natural gas fired turbines. In other areas, the coating microstructure and composition indicated a combination of oxidation and sulfidation.

The formation of sulfides on the surface of hot gas path parts is not normally desired. Metals sulfidize rather than oxidize only when it is more thermodynamically and kinetically favorable to 
do so. There are three major factors that influence the oxidation/sulfidation behavior of an alloy: the partial pressure of oxygen, the partial pressure of sulfur and the temperature. The partial pressure of oxygen is held relatively constant by the amount of cooling air flow and the temperature of the part is relatively constant during firing for efficiency reasons. This leaves the sulfur as the main variable in the equation. The sulfur that reaches the hot gas path originates from the fuel. If the amount of sulfur in the fuel reaches a high enough value, the alloy will form sulfides on the surface rather than oxides. These preliminary results, in addition to the further planned research, will equate to a substantial understanding of the effect of Coal IGCC combustion on hot gas path parts. With an understanding of the environment in the hot gas path, screening material performance to determine the magnitude and the mechanisms of materials degradation in a Coal IGCC environment will be made possible.

\section{Interaction Life Model Development}

Physically-based crack initiation models suitable for DS Ni-base superalloys are currently being developed based on the microstructural damage mechanisms observed in DS GTD-111. Two steps are required to complete the formulation: (1) characterize the evolution of micromechanisms responsible for crack initiation and (2) define and correlate the appropriate microstructural parameters that mathematically represent the microstructural state. The damage mechanisms that have the most dominant impact on residual life are related to fatigue (generation and movement of dislocations; fracture and debonding of inclusions, primarily carbides), creep (microcracking and cavitation at carbide inclusions and $\gamma / \gamma^{\prime}$ eutectics), and environment (embrittlement of surface layers and carbide phases). A cumulative damage model, along with parametric equations, is being developed to account for these mechanisms based on given operating conditions and pre-exposure histories. Validation and model parameters will be determined through observations from tests that isolate one or at most two of the mechanisms.

Based on life and deformation responses from preliminary experiments (Gordon et al., 2002), the crack initiation life can be predicted by simulating the cyclic response of the material under imposed isothermal and non-isothermal fatigue conditions. A viscoplasticity model developed by Shenoy and others (Shenoy et al., 2002; Shenoy et al. 2004) was implemented in ABAQUS ${ }^{\circledR}$ as a user-defined material (UMAT). This model also includes anisotropic generalized Hooke's Law and crystallographic orientation effects. The viscoplastic flow rule describes the effects of dislocation motion to the macroscopic deformation of a grain. The shear strain rate on the $\alpha^{\text {th }}$ slip system is given as

$$
\mathcal{K}^{(\alpha)}=\operatorname{\& } \Theta(T)\left\langle\frac{\left|\tau^{(\alpha)}-\chi^{(\alpha)}\right|-\kappa^{(\alpha)} \frac{\mu}{\mu_{0}}}{D_{0}}\right\rangle^{n} \exp \left\{B_{0}\left\langle\frac{\left|\tau^{(\alpha)}-\chi^{(\alpha)}\right|-\kappa^{(\alpha)} \frac{\mu}{\mu_{0}}}{D_{0}}\right\rangle^{n+1}\right\} \operatorname{Sgn}\left(\tau^{(\alpha)}-\chi^{(\alpha)}\right)
$$

where $D_{0}$ is the drag stress, $\tau^{(\alpha)}$ is the resolved shear stress, and $\chi^{(\alpha)}$ and $\kappa^{(\alpha)}$, are the back stress and threshold stress, respectively. Simulated hysteresis data (i.e., $\Delta \varepsilon_{i n}$ and $\sigma$ ) of a stabilized cycle is used to compute the accumulated fatigue, creep, and environmental damage. Additional details concerning the development and application of the constitutive model crack initiation model can be found in a publication that has been recently prepared for presentation at a technical conference (Gordon et al., 2005) and a PhD proposal (Shenoy, 2004). 
Preliminary mathematic formulations were developed to relate each mechanism ( $f a t, c r$, and env) to temperature, grain orientation, hold times, etc. The fatigue damage mechanism is related by

$$
N_{i}^{\text {fat }}=C_{1} f_{1}\left(\Delta \varepsilon_{\text {in }}\right)^{C_{2}}
$$

where $C_{1}$ and $C_{2}$ are constants and $f_{1}$ is a factor that accounts for material orientation (i.e., $\mathrm{L}$ or $\mathrm{T})$. To characterize this relation, data is needed from low temperatures, high strain rates, and $\mathrm{CC}$ tests. Tests conducted at and below $871^{\circ} \mathrm{C}$ were used to correlate Eq. (4).

The creep-fatigue interaction mechanism was found to correlate to

$$
N_{i}^{c r}=C_{3} \Theta_{c r}(T, t)\left(\frac{t_{c}+t_{h}}{t_{c}+2 t_{h}}\right)^{f_{2}}\left(\Delta \varepsilon_{i n}\right)^{C_{4}}
$$

where $C_{3}, C_{4}$, and $f_{2}$ are constants. The inelastic strain range, $\Delta \varepsilon_{i n}$, is used here since it captures orientation and time dependent deformation. The diffusion coefficient, $\Theta_{c r}$, along with the cycle and dwell times, given by $t_{c}$ an $t_{h}$, respectively, account for time and temperature-dependent degradation such as void nucleation and growth not captured in Eq. (4). The diffusion term is

$$
\Theta_{c r}(T, t)=\frac{1}{t_{c}} \int_{0}^{t_{c}} \exp \left(-\frac{Q_{c r}}{R T(t)}\right) d t
$$

Here $Q_{c r}$ is the activation energy, $T(t)$ is the temperature history, and $R$ is the gas constant. Specimens subjected to dwell times experience the most significant stress relaxation caused by viscoplastic deformation. The correlation of Eq. (5) involved HT and HC tests above $871^{\circ} \mathrm{C}$.

The term relating environment-fatigue interaction to crack initiation is motivated by the oxide spiking mechanism. The interaction is related to cycle-dependent repeated fracture of the oxide film. This process is controlled by $\Delta \varepsilon_{e}$, the oxidation growth kinetics, and the phasing between the mechanical and thermal loading captured through a phasing factor, $\Phi_{o x}$,

$$
N_{i}^{o x}=C_{5}\left[\Phi_{o x} \Theta_{o x}\left(t_{c}+t_{h}\right)\right]^{C_{6}} \Delta \varepsilon_{e l}{ }^{C_{7}}
$$

Here $C_{5}, C_{6}$, and $C_{7}$ are constants. The cycle time and diffusion factor, $\Theta_{o x}$, similar to Eq. (6) with $Q_{o x}$ capture the oxide film growth kinetics. The phasing factor is given by

$$
\Phi_{o x}=\exp \left[-C_{8}(\underset{i n}{\&} / \&+1)^{2}\right]
$$

This factor has a maximum value of unity for linear OP TMF, the condition most susceptible to the oxide spiking mechanism. Hysteresis data from isothermal tests above $871^{\circ} \mathrm{C}$ with dwells and TMF tests were used to determine the constants for Eqs. (7) and (8). The constants for Eqs. (4)-(8) are listed in Table 4.1.5.

Some trends that the model predicts are shown in Fig. 4.1.5 for continuously-cycled L-oriented DS GTD-111 specimens. For both isothermal (Fig. 3a) and non-isothermal (Fig. 3b) cases, the crack initiation life is characterized by the constitutive response at high mechanical strain ranges since the fatigue term dominates. Under isothermal conditions, the change in slope of predicted life below the mechanical strain range of $1.0 \%$ relates to a changeover from predominantly fatigue to coupled environment-fatigue mechanism. As the temperature is decreased below $871^{\circ} \mathrm{C}$, there is insufficient thermodynamic energy to drive oxidation, and the role of environment is limited as a result. Under TMF conditions at lower mechanical strain ranges 
(Fig. 3b), the OP cycle is predicted to be more damaging than the IP cycle. This prediction is consistent with experiments since the oxide spiking, which is more detrimental to life than oxide spallation, is experienced during OP cycling. During IP cycling with $\Delta \varepsilon_{m}<1.0 \%$, life is dominated by the fatigue mechanism. With the increase of $\Delta T$ from $389^{\circ} \mathrm{C}$ to $500^{\circ} \mathrm{C}$, the constitutive model predicts $\Delta \varepsilon_{\text {in }}$ to increase.

Table 4.1.5 Constants for the Crack Initiation Model

\begin{tabular}{cccccc}
\hline \multicolumn{2}{c}{ Fatigue Term } & \multicolumn{2}{c}{ Creep-Fatigue Term } & \multicolumn{2}{c}{ Environment-Fatigue Term } \\
\hline Symbol & Value & Symbol & Value & Symbol & Value \\
\hline $\mathrm{C}_{1}$ & 0.15 & $\mathrm{C}_{3}$ & 60 & $\mathrm{C}_{5}$ & 0.10 \\
$\mathrm{C}_{2}$ & -0.65 & $\mathrm{C}_{4}$ & -1.10 & $\mathrm{C}_{6}$ & -0.57 \\
$\mathrm{f}_{1}$ & 0.78 & $\mathrm{f}_{2}$ & 1.00 & $\mathrm{C}_{7}$ & -0.45 \\
& & $\mathrm{Q}_{\mathrm{cr}}(\mathrm{J} / \mathrm{mol})$ & 6752 & $\mathrm{C}_{8}$ & 0.50 \\
& & & $\mathrm{Q}_{\mathrm{ox}}(\mathrm{J} / \mathrm{mol})$ & 164000 \\
\hline
\end{tabular}
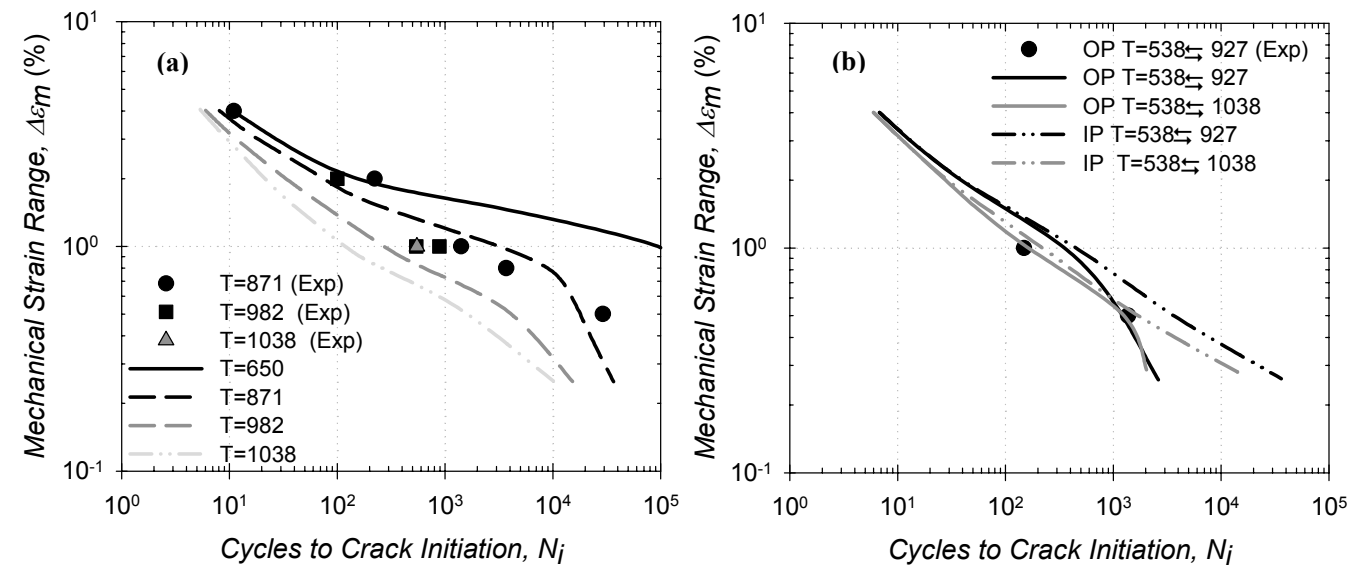

Figure 4.1.5 Predictions for (a) isothermal LCF and (b) TMF of L DS GTD-111

In identical sets of tests conducted when the mechanical strain range was the same for $\mathrm{L}$ and $\mathrm{T}$ oriented DS GTD-111 specimens, the inelastic strain ranges for $\mathrm{T}$ specimens is greater. Consequently, the lives of $\mathrm{L}$ specimens typically outlast those of $\mathrm{T}$ on a basis of $\Delta \varepsilon_{m}$. The crystallographic orientation dependence in the constitutive model captures this phenomenon, predicting the trends especially at higher mechanical strain. Additional details concerning the crack initiation model can be found in publications that have been recently prepared for presentation at technical conferences (Gordon et al., 2005; Shenoy et al. 2004). A thorough description of the fatigue testing program is given in a $\mathrm{PhD}$ proposal (Gordon, 2004). 


\section{Fracture Mechanics Model Development}

\section{Creep Crack Growth Modeling}

The creep deformation and rupture behavior and creep crack growth behavior of a directionally solidified nickel-based superalloy have been characterized and models applied to support remaining-life calculations. The tensile creep behavior consistently shows a very short primary creep regime, followed by a substantial steady-state region that accounts for more than half of the creep life but only between $20 \%$ to $33 \%$ of the creep strain. Subsequently, a tertiary creep stage develops that is responsible for less than half of the creep life but for the majority of the accumulated creep strain. The longitudinal orientation shows a longer creep life, larger final elongation and lower minimum strain rate than the transverse one and than the equiaxed material. The differences become smaller at higher temperatures. The time to rupture for any creep test at any combination of temperature and stress in the range studied can be accurately predicted by the Larson Miller parameter, the rupture model based on secondary power law creep coupled with the Monkman-Grant rupture criterion and by the theta projection model. The creep deformation behavior can be predicted by the power law model and by the theta projection model. Creep crack growth specimens tested in the LT orientation presented lower crack advance rates than the TL orientation and were completely correlated by $C_{t}$. Furthermore, a single relationship between, creep crack growth rate and $C_{t}$ was applicable to all temperatures and both orientations. Further details detailing the experimental procedure and the model are given in a recent paper by Ibanez and others (Ibanez et al., 2005).

\section{Creep-Fatigue Crack Growth Model}

A mathematical model based on the physics of thermally activated dislocation motion has been developed to represent the effects of temperature over a wide range for a DS GTD-111 Ni base alloy in the LT and TL orientations. The model predictions compares well with extensive amounts of fatigue crack growth data also developed as part of the study. The derivation of the model and the regression fit are described in a recent paper written by Yoon and coworkers (Yoon et al., 2005).

\section{Fractography}

The fracture surface on the LCF specimens was studied on the SEM to identify the microstructural features which would contribute to crack initiation. Carbide inclusions were observed on the fracture specimens at the crack initiation sites. This was observed in the both the longitudinal and transverse specimens as shown in Figs 4.1.6 and 4.1.7. The carbides were $10-40 \mu \mathrm{m}$, and were oxidized, and also contained $\mathrm{Si}$ and/or $\mathrm{Cr}$ and/or Ti.

\section{Computational Study}

A study of the drivers for crack growth when cracks incubate at inclusions or other discontinuities in the microstructure is on-going. Transfer functions are being developed to relate these local drivers (maximum cyclic plastic shear strain range and the cyclic crack tip displacement) to remotely applied cyclic loading. A parametric study is being conducted to find the dependence of the drivers on crack length, loading conditions, crystallographic orientation, and other microstructural discontinuities (i.e., shape and state of MC carbide inclusions). An environment-fatigue coupling can be incorporated into this modeling framework based on Miller and colleagues (Miller et al. 1992). 

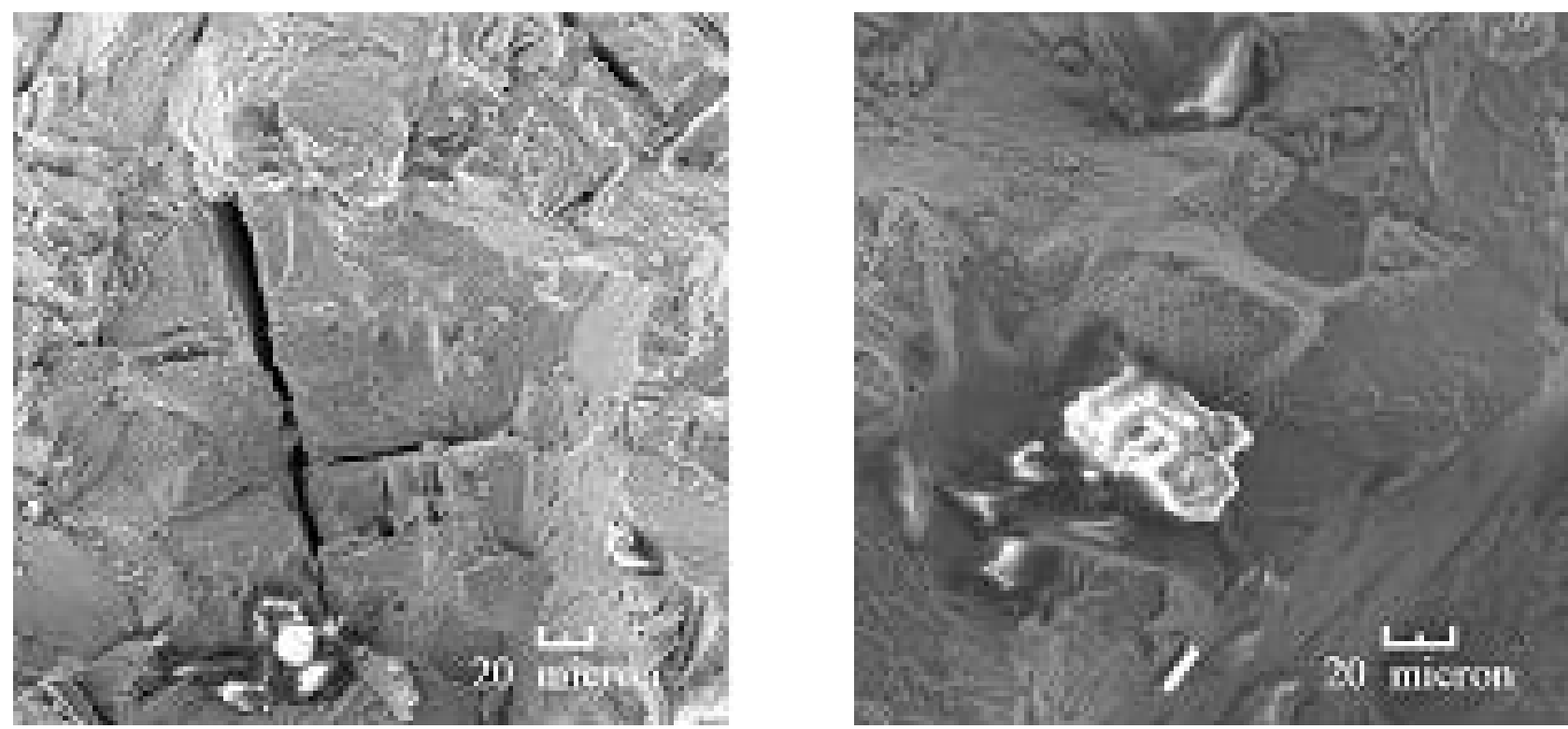

Figure 4.1.6 (a) A debonded carbide on the fracture surface (longitudinal specimen, $1600{ }^{\circ} \mathrm{F}$, continuous cycling) and (b) Inclusion on the fracture surface acting as a crack initiation site (transverse specimen, $1600^{\circ} \mathrm{F}$, cycling with compression hold time)

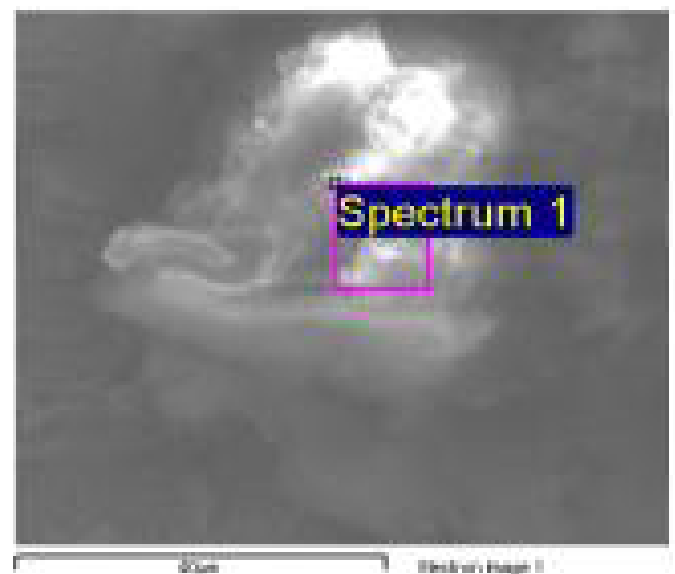

\begin{tabular}{|c|c|c|c|c|}
\hline ETemert & AnpP & Irterntstr & We & Atomi $\%$ \\
\hline L $\mathrm{F}$ & 440.93 & 1.00 & 60.76 & 6806 \\
\hline $0 \mathrm{~K}$ & 9591 & 0.36 & 36.62 & 30.79 \\
\hline $\operatorname{sir}$ & 1308 & 0.86 & 2.09 & 1.00 \\
\hline $\mathrm{L} 1 \mathrm{~K}$ & 0.94 & 0.82 & 0.16 & 0.06 \\
\hline $\mathrm{Fe} \mathrm{K}$ & 1.00 & 0.81 & 0.17 & 0.04 \\
\hline $\mathrm{HiK}$ & 1.18 & 0.81 & 0.20 & 0.05 \\
\hline
\end{tabular}

Figure 4.1.7 Chemical composition of a carbide inclusion on the fracture surface (transverse specimen, $1600^{\circ} \mathrm{F}$, cycling with compression hold time) 


\section{Task 2 Status/Discussion:}

Overview: Under this task new technologies to determine the health of advanced technology Coal IGCC powerplants will be evaluated and demonstrated. Technologies developed for the aerospace industry will be highly leveraged via collaborations and SNL. The task has been divided into the following subtasks:

Subtask 2.1 - Define Coal IGCC Powerplant Requirements: Monitoring requirements will be established for Coal IGCC and natural gas powerplants. Needs will be identified and prioritized using Quality Function Deployment (QFD) and other "Six Sigma" quality tools that are now used widely throughout GE. The Critical-To-Quality (CTQ) characteristics of the required sensors and systems will be identified during this process.

Subtask 2.2 - Sensor Capability Studies: Laboratory trials will be performed to baseline the accuracy and repeatability of the fuel quality sensor including the fuel heating value sensor. The technologies specifically will include the new fuel quality sensor developed with SNL under the DOE Smart Power Turbine program. The capability of the fuel quality sensor will be tailored specifically for Coal IGCC fuel constituents.

Subtask 2.3 - IR Pyrometer for Condition Based Maintenance: Infra-Red (IR) pyrometer temperature measurements will be validated using experimental data from the laboratory and field data from at least two turbine installations. The pyrometer data will be compared to predictions of metal temperature from aerodynamic and heat transfer models. Factors that affect the pyrometer temperature measurement and causes of errors will be evaluated. These include pyrometer alignment, lens fogging, surface coatings (particularly TBC), radiation and surface emissivity effects, and operational variables (e.g. water/steam injection, vibration, operational mode, fuel type, etc.) and line of sight.

Subtask 2.4 - Field Deployment and System Validation: Field trials of the fuel quality sensor including the heating value sensor will be performed at Coal IGCC and Syngas facilities. Experiments to verify that the advanced sensor technologies will meet the requirements of the power plant environment will be performed. Powerplant integration, IT compatibility and environmental issues will be identified.

\section{Task 2 Discussion:}

\section{Subtask 2.1 - Define Coal IGCC Power Plant Requirements:}

This task is complete. The critical sensors for Coal IGCC gas turbines have been defined: measurement of fuel quality and heating value, hot gas path (HGP) TBC loss and metal temperature, combustion flame temperature, and combustion dynamics. Figure 4.2.1 gives the ranking of the sensor requirements for Coal IGCC gas turbine monitoring. 


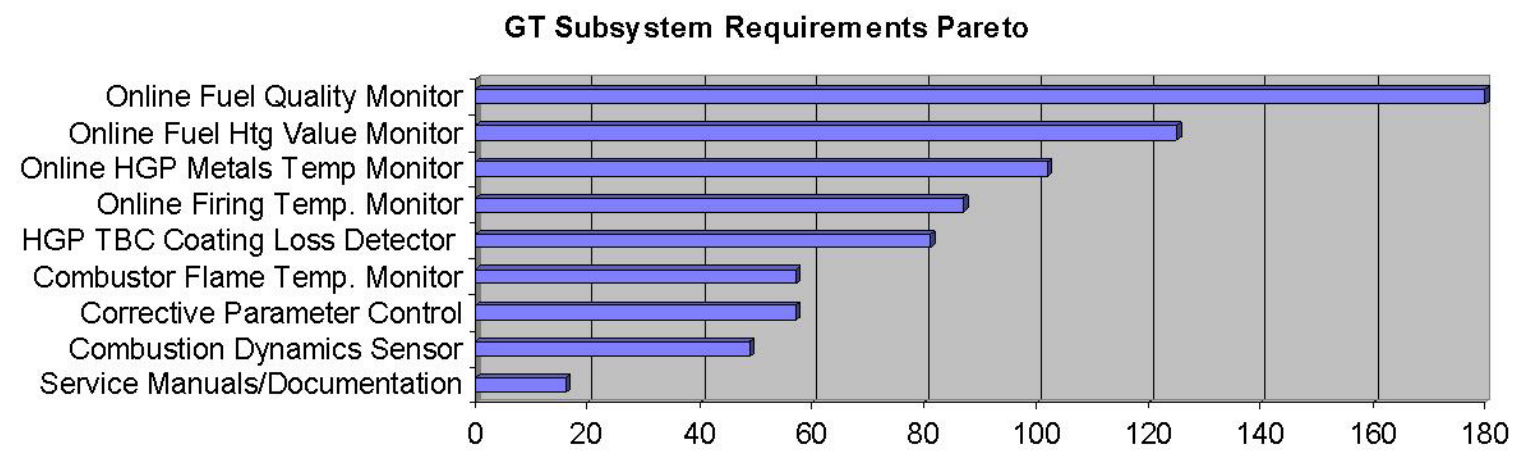

Figure 4.2.1 Sensor requirements for Coal IGCC gas turbines

\section{Subtask 2.2 - Sensor Capability Studies:}

Coal IGCC gas turbine monitoring sensors are needed, in order of priority, for measurement of fuel quality, fuel heating value, hot gas path metal temperature, firing temperature, TBC coating loss, combustion flame temperature, exhaust emissions (needed for corrected parameter control), and combustion dynamics. Some of these requirements can be met simultaneously with one sensor; for example, hot gas path metal temperature, firing temperature, and TBC coating loss may possibly all be determined using the pyrometer.

The fuel quality and heating value sensor and the pyrometer will be further developed and demonstrated in Coal IGCC gas turbines under this program.

\section{Fuel LHV Sensor Flow Optimization and Calibration}

Simple tests of single natural gas constituents; including methane $\left(\mathrm{CH}_{4}\right)$, ethane $\left(\mathrm{C}_{2} \mathrm{H}_{8}\right)$, and $\mathrm{CO}$; were performed. Figure 4.2.2 shows the signals for pre-combustion ethane, post-combustion ethane, and post-combustion $\mathrm{CO}_{2}$. The $\mathrm{CO}_{2}$ results indicate an increase in combustion until $\sim 6 \%$ ethane concentration, after which the combustion decreases slowly. It should be noted that $\mathrm{CO}$ was not present in the exhaust at appreciable concentrations, indicating that combustion is proceeding primarily to $\mathrm{CO}_{2}$. Figure 4.2.3 shows the LHV sensor signal over the same range of concentrations, and validates the interpretation of decreasing combustion with higher ethane concentrations. Figure 4.2.4 shows results for $\mathrm{CO}$; in this case, combustion appears to maintain its efficiency independent of concentration, as indicated by increasing $\mathrm{CO}_{2}$ in the exhaust. Results for ethane and other natural gas constituents indicate that some mechanism is responsible for limiting the combustion reaction. Since GC analysis shows an abundance of oxygen exists in the fuel exhaust, the catalytic combustion on the sensor's surface is likely mass-transfer or reaction-rate limited. 


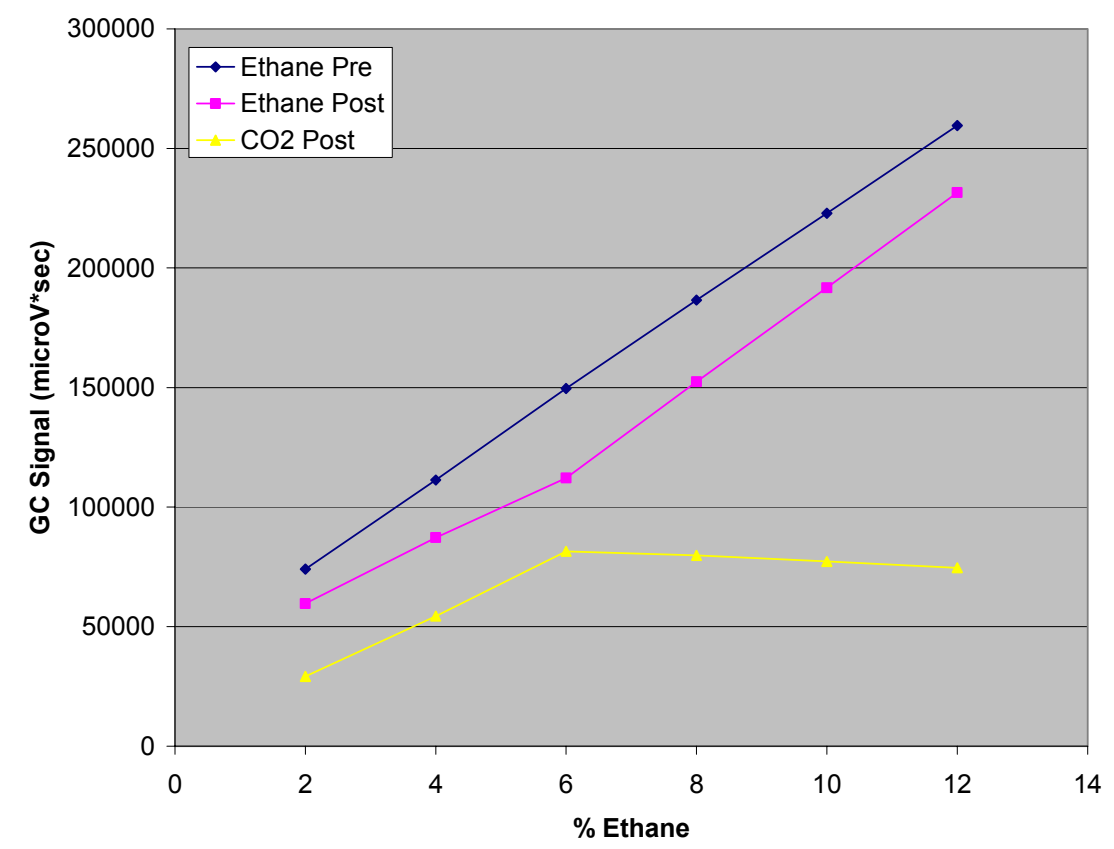

Figure 4.2.2 Combustion effects on ethane and $\mathrm{CO}_{2}$

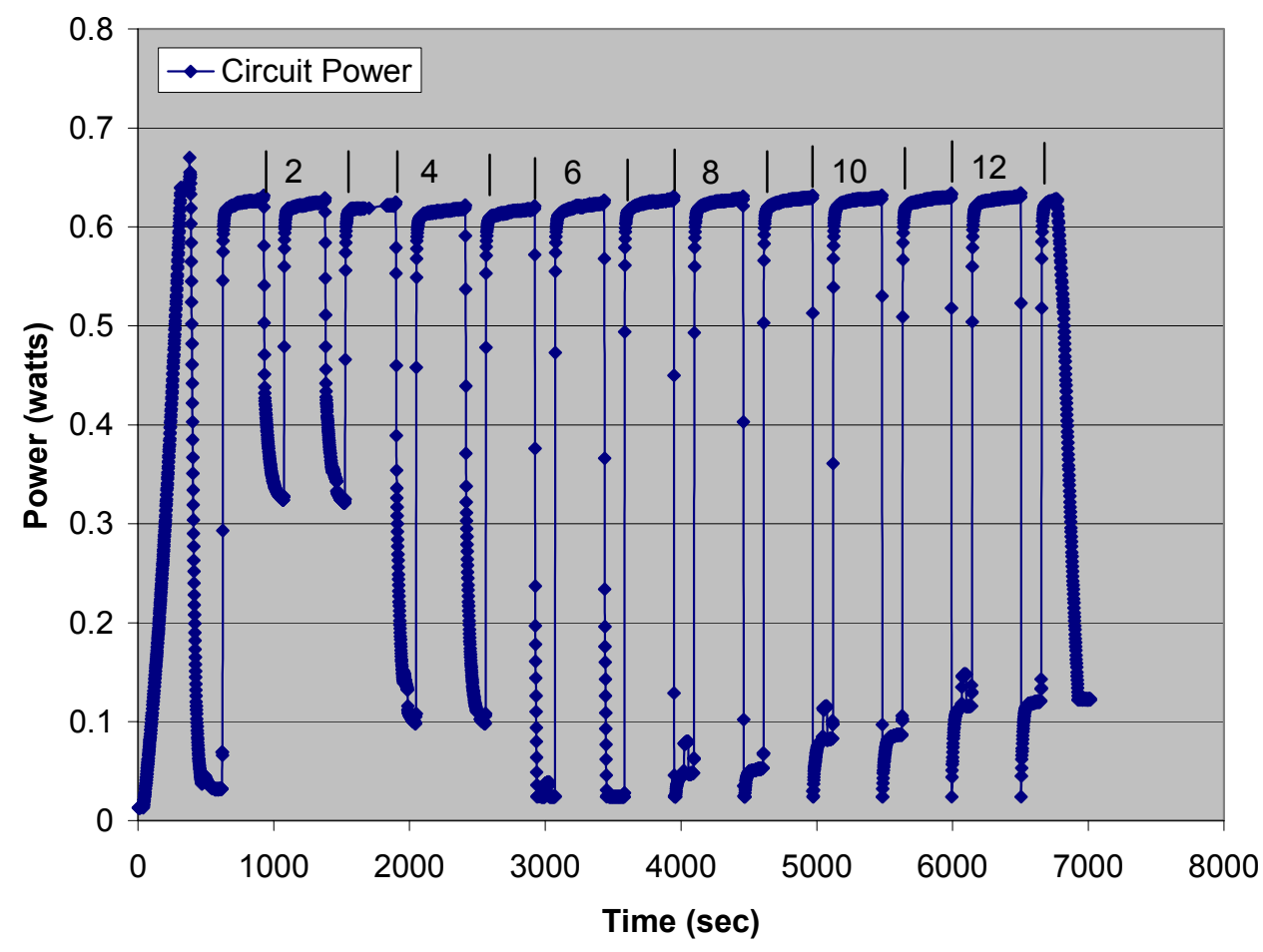

Figure 4.2.3 LHV sensor signal responding to varying concentrations of ethane 


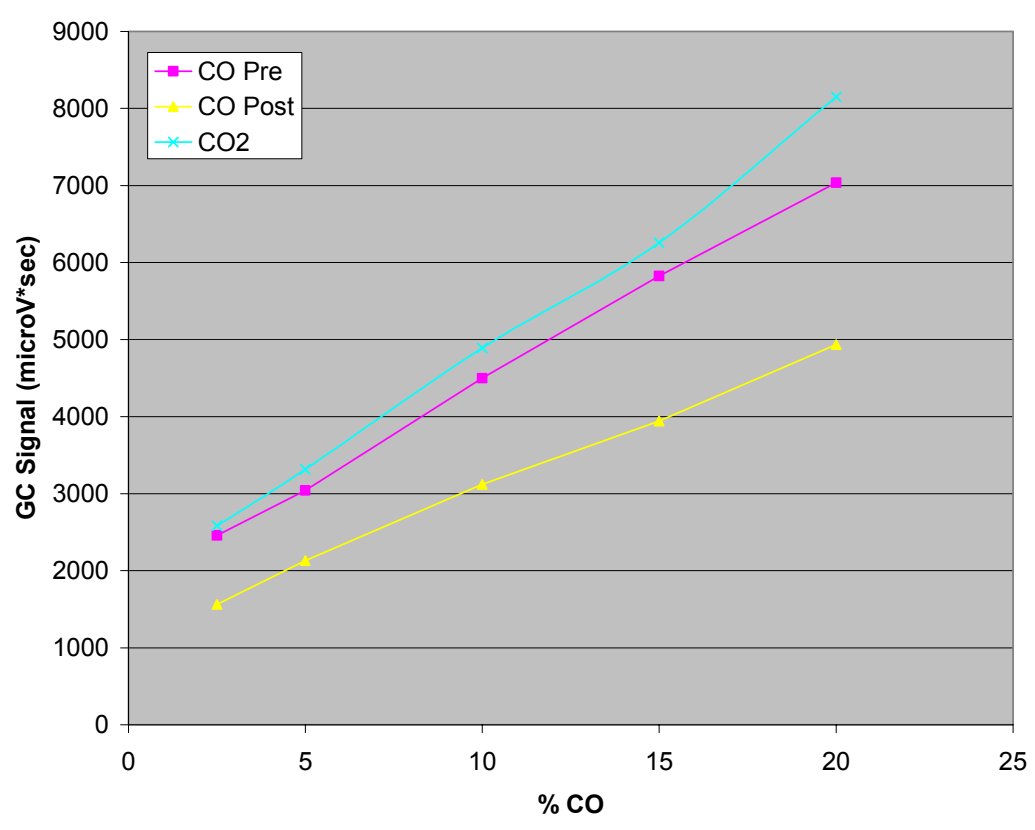

Figure 4.2.4 Combustion affects on $\mathrm{CO}$

Analysis of test results using the natural gas standards, which are more complex hydrocarbon mixtures of $\mathrm{C} 1-\mathrm{C} 5$, shows similar results. Figure 4.3 .5 shows the \% change of each hydrocarbon constituent. This indicates that combustion efficiency is a function of both the hydrocarbon order and the natural gas concentration. Of note is the poor combustion of methane, independent of concentration. When methane is tested alone it exhibits both stronger conversion and a point of maximum combustion at $\sim 15 \%$. The difference in combustion efficiencies between methane in a fuel mixture and singularly indicates the presence of competing reaction mechanisms. The point of maximum combustion for the natural gas standard 303102, indicated by a peak in the carbon dioxide concentration, appears to be around 8\%. Carbon monoxide emissions in the exhaust are extremely small, indicating nearly complete combustion for those constituents that undergo reaction. Test on other natural gas and Syngas mixtures are ongoing.

\section{Optimization of Sensor Parameters for Syngas Fuels}

Representative data from the optimization experiments is shown in 4.2.6. A number of designed experiments were run to find the ideal temperature and fuel to air ratio (phi) at which to operate the sensor with Syngas fuels. In the plot shown, the percentage of Syngas in the total flow is increased with time moving from left to right (i.e. phi is increasing). Each peak is a different percentage, with the fuel flow stopped in between each. When there was no fuel flowing, the base amount of air $(30 \mathrm{sccm})$ was flowing. For each peak, an average value and standard deviation was obtained. The overall goal was to maximize the average value and minimize the standard deviation. From these experiments, it was determined that the sensor can be operated over a rather broad range of phi values, ranging from about 0.4 (lean mixture) to 1.1 (rich mixture). Obviously, to obtain accurate measurements of LHV, total combustion of the fuel needs to take place in the sensor; thus, flows where kept in the lean regime. Finally, from the optimum flow ratios, ideal orifice sizes where calculated for the field tests. 


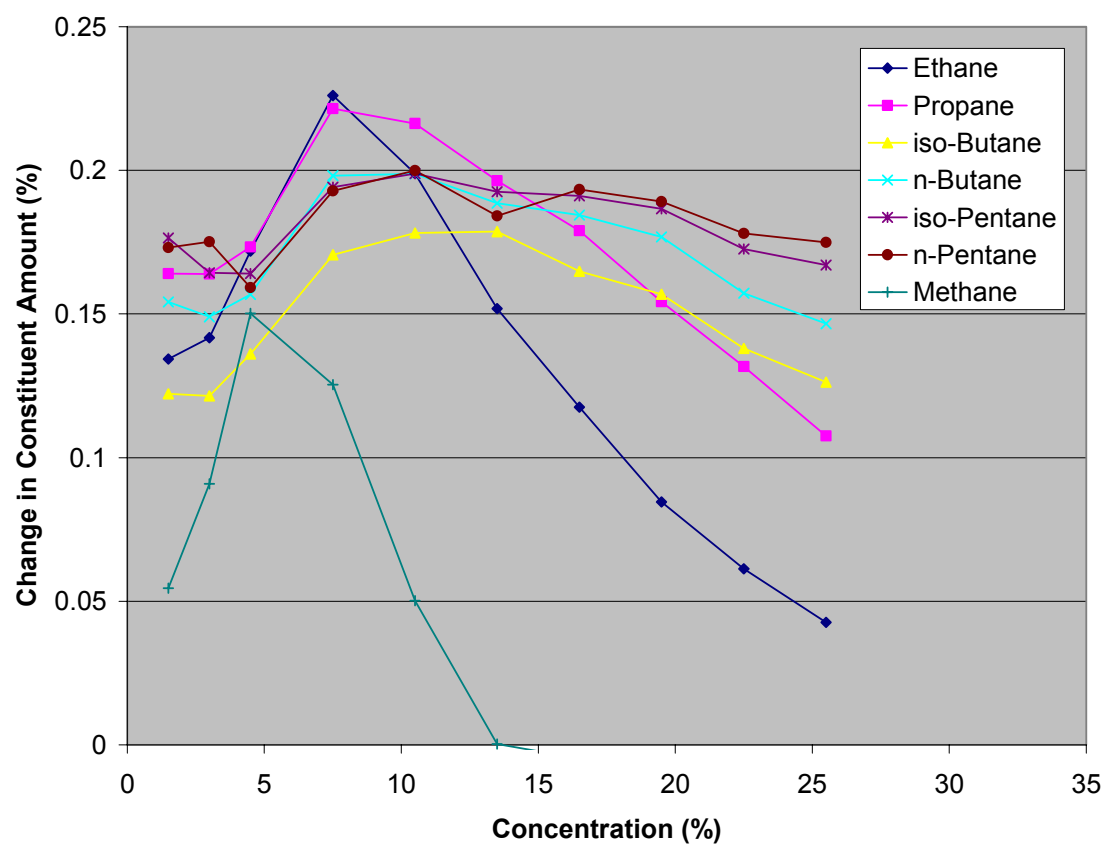

Figure 4.2.5 Percent change of natural gas constituents by concentration

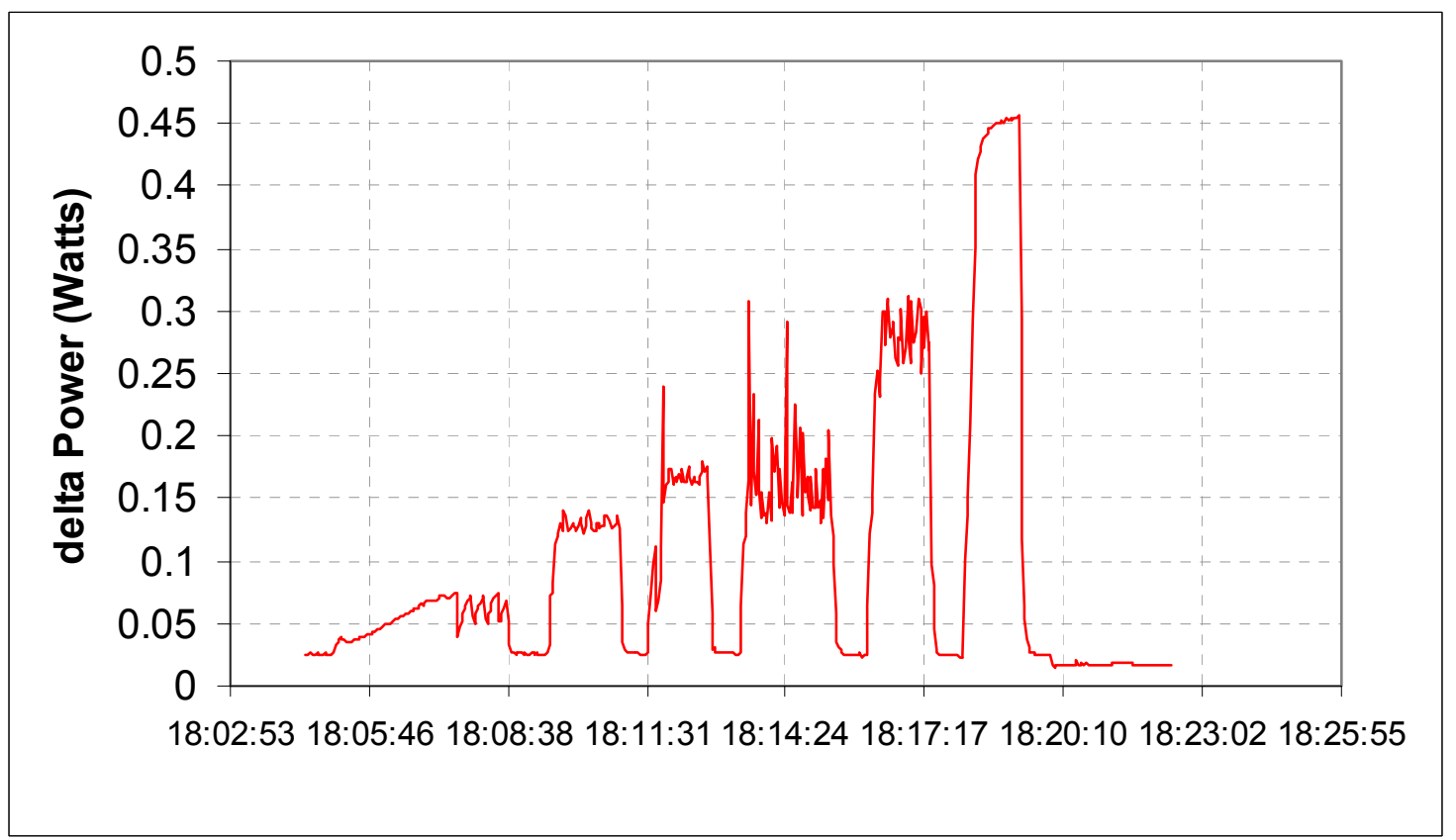

Figure 4.2.6 Sensor output versus time. Each plateau corresponds to a change in the Syngas to air ratio. 


\section{Subtask 2.3 - IR Pyrometer for Condition Based Maintenance:}

Progress is reported on the following activities:

1. Calibration of the pyrometers at the Cinergy/PSI Wabash River Station

2. Developing a methodology to determine condition of the buckets

\section{Calibration of the pyrometers at the Cinergy/PSI Wabash River Station}

Details of the calibration of the five pyrometers used on the gas turbine are shown in Table 4.2.1.

Table 4.2.1 PSI-Cinergy IGCC gas turbine pyrometer calibration details

\begin{tabular}{|l|c|c|c|}
\hline Position & $\begin{array}{c}\text { Before Cleaning } \\
{ }^{\circ} \mathrm{C}\end{array}$ & $\begin{array}{c}\text { Clean Top } \\
{ }^{\circ} \mathrm{C}\end{array}$ & $\begin{array}{c}\text { Clean Bottom } \\
{ }^{\circ} \mathrm{C}\end{array}$ \\
\hline B1F & 862 & 909 & 953 \\
\hline B1A & 928 & 941 & $953 / 947^{*}$ \\
\hline B2F & 923 & 944 & 953 \\
\hline B2A & 926 & 939 & 952 \\
\hline B3F & 913 & 940 & 951 \\
\hline
\end{tabular}

*B1A sightglass was found to have a baked on stain that could not easily be removed, the two readings indicate the best and worst readings measured by the Cyclops 152 pyrometer.

\section{Methodology to Determine Condition of the Buckets}

As part of the long-term IR pyrometer data collection from the Duke Energy gas turbines (Moss Landing and Maine Independence powerplants), a boroscope inspection was performed at the Moss Landing plant during their Combustion Inspection outage in June. Two main tasks were accomplished during this inspection: 1) routine pyrometer maintenance and 2) visual inspection of the Stage 1 buckets via boroscope for comparison with pyrometer and thermal imaging data.

\section{Pyrometer maintenance}

The pyrometer hardware was found to be in good repair. The window on the alignment flange had some minor fogging. This was cleaned prior to re-installing the alignment flange. The pyrometer was re-aligned using a Land telescope.

\section{Bucket inspection}

The Stage 1 turbine buckets were imaged via a boroscope through the plug on the side of the pyrometer alignment flange. A laser pointer, shown through the pyrometer flange, was used to indicate the cold pyrometer line of sight.

To obtain the single bucket motion of the turbine, the turbine was hand cranked with a ratchet. The once-per-revolution key phasor signal was monitored while the turbine was rotated until a 
negative voltage was observed from the connected oscilloscope. The triggering of the key phasor indicates bucket number 1 in relation to the pyrometer data acquisition system. From this point all of the buckets were imaged to observe known areas of wear and other damage.

The condition of each bucket was characterized as to the location and magnitude of observable degradation. Four buckets appeared to have degraded more than the others. The information is being used to determine if the observed degradation can be predicted by the pyrometer and thermal imaging data.

\section{Subtask 2.4 - Field Deployment and System Validation:}

\section{Syngas field test of the LHV Sensor}

The sensor was very robust and reliable over the duration of the testing at PSDF. There was no experience using the sensor in a harsh environment prior to this test. The same set of sensing elements were used for the entire test. This includes operation on the raw gas stream at $176.7^{\circ} \mathrm{C}$, which contained approximately $20 \%$ water vapor and approximately $200 \mathrm{ppm} \mathrm{of} \mathrm{H}_{2} \mathrm{~S}$.

A representative series of data that shows the sensor's response to changes in gas conditions is shown in Figure 4.2.7. At the left of the plot, an $\mathrm{O}_{2}$-blown gasification process was used, while at the right of the plot, an Air-blown process was used. During this transition, the heating value of the fuel stream dropped by approximately one half. The transition between the two processes took place over a 15 minute period. The LHV sensor took a longer time to respond than the GC, although the GC required additional time to stabilize to the correct value. After the GC stabilized, the relative change in sensor output versus the relative change in heating value measured by the GC showed a fairly good correlation.

Analysis of the data to correct for changes in mass flow and to extract a calibrated LHV value is ongoing. The slower response of the LHV sensor may have been caused by the large volume of tubing between the gas tap and the sensor, as well as the small flow rates used. The nature of the LHV sensor allows for very fast response to changes in fuel composition. The slow response at PSDF was due to the configuration and volume of the system plumbing. This will be addressed during future testing. 


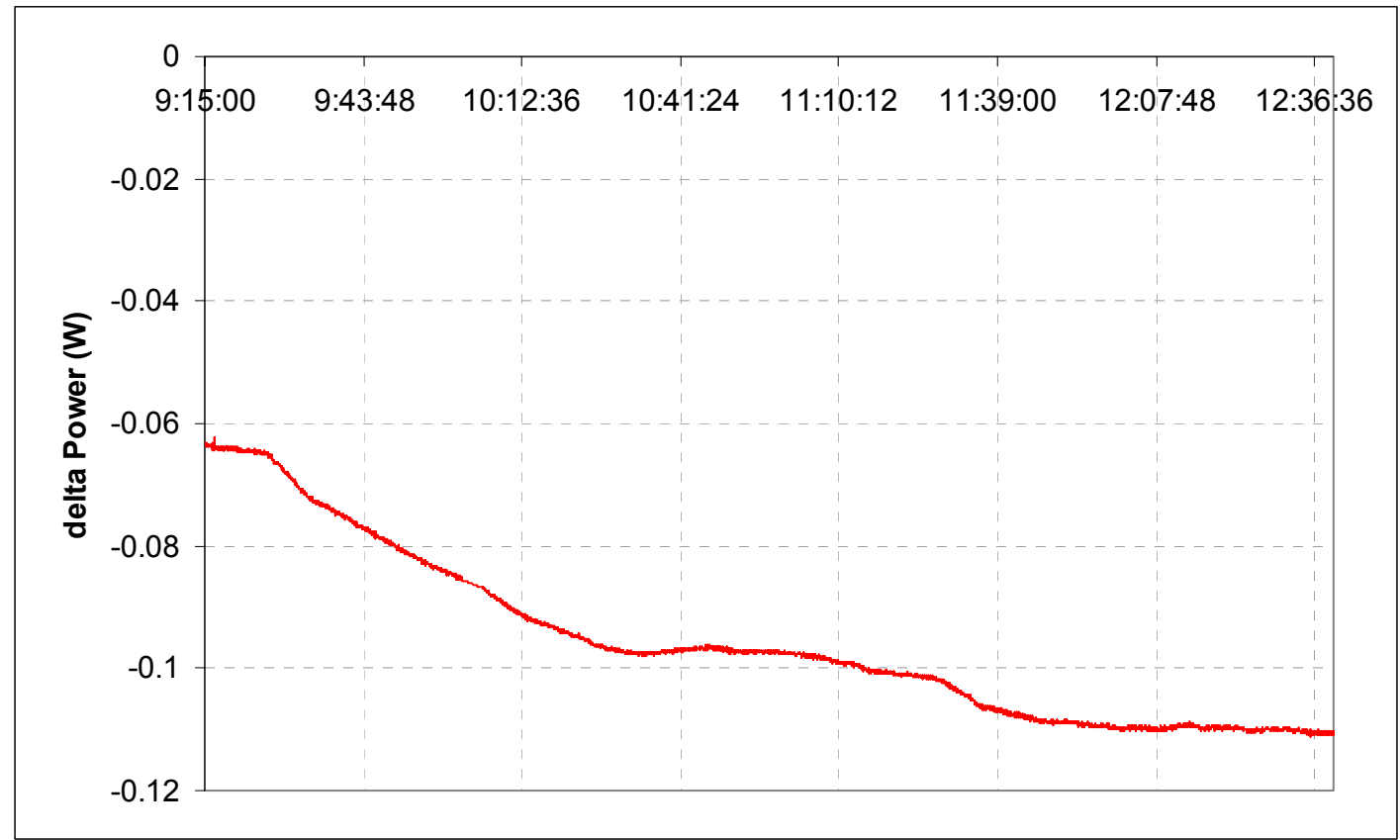

Figure 4.2.7 LHV sensor output versus time. At the left of the plot the Syngas was generated via an $\mathrm{O}_{2}$-blown process, while on the right it was generated via an air-blown process. 


\subsection{Conclusions}

\section{Task 1- COAL IGCC Environmental Impact on High Temperature Materials:}

TECo has provided serviced hot gas path parts for microscopic analysis. The preliminary analysis of a Stage 1 bucket has indicated that the environment the part encountered altered the corrosion product on the surface. In some areas, the coating microstructure and composition indicated typical oxidation behavior seen in natural gas fired turbines. In other areas, the coating microstructure and composition indicated a combination of oxidation and sulfidation.

Physics-based life models for DS GTD111 are being developed by the Georgia Institute of Technology, with an emphasis on the interactions between creep, fatigue and environmental effects.

\section{Task 2 - Material In-Service Health Monitoring:}

Capability evaluations of the fuel quality and heating value sensor by Sandia National Lab and the GE Global Research Center continue to show progress. This sensor will provide online information on the variability of fuel properties, which will enable improvements in the control of Coal IGCC gas turbines. The sensor was successfully tested for a week at the PSDF IGCC facility in Wilsonville, AL.

The methodology of predicting temperature of the buckets is being improved using updated analysis tools, and a methodology to determine and report the condition of the buckets in real time has been developed. Pyrometers were re-commissioned on the Cinergy/PSI Wabash River Station GE 7FA IGCC gas turbine, and the Stage 1 buckets were inspected on the Duke Energy Moss Landing GE 7FA+e gas turbine. 


\subsection{References}

1. Gordon, A. P., McDowell, D. L., and Neu, R. W. (2002) "Low Cycle Fatigue of GTD111-DS at Elevated Temperatures" Technical Report, Georgia Institute of Technology, Atlanta, GA.

2. Gordon, A. P., (2004) "Crack Initiation Modeling of a Directionally-Solidified Ni-base Superalloy” PhD Proposal, Georgia Institute of Technology, Atlanta, GA.

3. Gordon, A. P., Shenoy, M. M., and Neu, R. W. (2005). "A Thermomechanical Fatigue Crack Initiation Model for Directionally-Solidified Ni-base Superalloy," 11th International Congress of Fracture (ICF11), Turin, Italy, Elsevier Science.

4. Ibañez, A. R., Saxena, A., and Kang, J. D. (2005) "Creep Behavior of a Directionally Solidified Nickel Based Superalloy," 11th International Congress of Fracture (ICF11), Turin, Italy, Elsevier Science.

5. Miller, M. P., McDowell, D. L., and Oehmke, R. L. T. (1992). "A Creep-FatigueOxidation Microcrack Propagation Model for Thermomechanical Fatigue." Journal of Engineering Materials and Technology, 114, 282-288.

6. Shenoy, M., Kang, M.-S., Neu, R.W., and McDowell, D.L., "Cyclic Deformation of a DS Ni-base Superalloy at $871^{\circ} \mathrm{C}$," proc. CAMP2002: High-Temperature Fatigue, G. Biallas, H.J. Maier, O. Hahn, K. Herrmann, and F. Vollertsen, Eds., Bad Lippspringe, Germany, 3-4 April 2002, pp. 14-28.

7. Shenoy, M. M., (2004) "Constitutive Modeling and Life Prediction in a Directionally Solidified Ni-Base Superalloy" PhD Proposal, Georgia Institute of Technology, Atlanta, GA.

8. Shenoy, M.M., Gordon, A.P., McDowell, D.L., and Neu, R.W., "Thermomechanical Fatigue Behavior of a Directionally Solidified Ni-base Superalloy," International Journal of Fatigue, Fifth International Conference on Fatigue Damage of Structural Materials, Hyannis, MA, September 19-24, 2004, submitted for review, September 2004.

9. Trexler, M. D. (2004) PhD Proposal, Georgia Institute of Technology, Atlanta, GA (to be presented October 2004).

10. Yoon, K. B., Park, T. G., Saxena, A., (2005) "Elevated Temperature Fatigue Crack Growth Model for DS GTD-111," 11th International Congress of Fracture (ICF11), Turin, Italy, Elsevier Science. 


\title{
7.0 List of Acronyms and Abbreviations
}

\author{
ASTM - American Society for Testing and Materials \\ CTQ - Critical To Quality \\ DMI - Duke Energy, Maine Independence Power Station \\ DML - Duke Energy, Moss Landing Power Station \\ DS - Directional Solidification \\ EPA - Environmental Protection Agency \\ GT - Georgia Institute of Technology \\ GC - Gas Chromatograph \\ GEAE - GE Aircraft Engines \\ GEPS - GE Power Systems \\ GRC - GE Global Research Center \\ GUI - Graphical User Interface \\ IGCC - Integrated Gasification Combined Cycle \\ HGP - Hot Gas Path \\ IP $\quad-$ In Phase (for TMF) \\ IR $\quad-$ Infra-Red \\ IT - Information Technology \\ KP - Key Phasor \\ LHV - Lower Heating Value \\ LIBS - Laser Induced Breakdown Spectrometry \\ LOS - Line Of Sight \\ MEMS - Micro-Electro-Mechanical System \\ MFC - Mass Flow Controller \\ OP $\quad-$ Out of Phase (for TMF) \\ PSDF - Power Systems Development Facility \\ QFD - Quality Function Deployment \\ RAM - Reliability, Availability, and Maintainability \\ RM\&D - Remote Monitoring and Diagnostics \\ SNL - Sandia National Laboratory \\ TBC - Thermal Barrier Coating \\ TECO - Tampa Electric Company \\ TGA - Thermo-Gravimetric Analysis \\ TMF - Thermo-Mechanical Fatigue \\ UG - Unigraphics \\ UOSM - Universal On-Site Monitor
}


